Article

\title{
European Rice Cropland Mapping with Sentinel-1 Data: The Mediterranean Region Case Study
}

\author{
Duy Ba Nguyen ${ }^{1,2, *}$ and Wolfgang Wagner ${ }^{2}$ \\ 1 Department of Geodesy and Geoinformation, Vienna University of Technology, Gusshausstrasse 27-29, \\ A-1040 Vienna, Austria \\ 2 Department of Photogrammetry and Remote Sensing, Hanoi University of Mining and Geology, \\ Hanoi 10000, Vietnam; wolfgang.wagner@geo.tuwien.ac.at \\ * Correspondence: nguyenbaduy@humg.edu.vn; Tel.: +43-680-243-4738
}

Academic Editors: Arjen Y. Hoekstra, Frédéric Frappart and Luc Bourrel

Received: 7 February 2017; Accepted: 26 May 2017; Published: 1 June 2017

\begin{abstract}
Rice farming is one of the most important activities in the agriculture sector, producing staple food for the majority of the world's growing population. Accurate and up-to-date assessment of the spatial distribution of rice cultivated area is a key information requirement of all stakeholders including policy makers, rice farmers and consumers. Timely assessment with high precision is, e.g., crucial for water resource management, market prices control and during humanitarian food crisis. Recently, two Sentinel-1 (S-1) satellites carrying a C-band Synthetic Aperture Radar (SAR) sensor were launched by the European Space Agency (ESA) within the homework of the Copernicus program. The advanced data acquisition capabilities of S-1 provide a unique opportunity to monitor different land cover types at high spatial $(20 \mathrm{~m})$ and temporal (twice-weekly to biweekly) resolution. The objective of this research is to evaluate the applicability of an existing phenology-based classification method for continental-scale rice cropland mapping using S-1 backscatter time series. In this study, the S-1 images were collected during the rice growing season of 2015 covering eight selected European test sites situated in six Mediterranean countries. Due to the better rice classification capabilities of SAR cross-polarized measurement as compared to co-polarized data, S-1 cross-polarized (VH) data were used. Phenological parameters derived from the S-1 VH backscatter time series were used as an input to a knowledge-based decision-rule classifier in order to classify the input data into rice and non-rice areas. The classification results were evaluated using multiple regions of interest (ROIs) drawn from high-resolution optical remote sensing (SPOT 5) data and the European CORINE land cover (CLC 2012) product. An overall accuracy of more than $70 \%$ for all eight study sites was achieved. The S- 1 based classification maps reveal much more details compared to the rice field class contained in the CLC 2012 product. These findings demonstrate the potential and feasibility of using S-1 VH data to develop an operational rice crop monitoring framework at the continental scale.
\end{abstract}

Keywords: rice mapping; Sentinel-1 A; SAR time series; remote sensing

\section{Introduction}

Europe is the fourth largest importer of rice in the world (Figure 1a). Over the last five years, Europe's annual rice imports were on average about 1 million tons (milled basis), ranging between 873 million tons in 2011 and 1190 million tons in 2015 [1]. Meanwhile, the size of rice cultivated areas has either reduced or remained stable around 420,000 hectares (Figure 1b). Information about how the area of rice croplands varies from year to year is an important piece of information for the European economy being relevant for: risk management for the insurance industry [2], environmental reporting, 
contributions to greenhouse gases [3], life cycle inventory [4,5], life cycle assessment [6,7], water cycle analysis [8], crop forecasting [9], and others.

According to the FAO Technical Guidelines, the standard procedure to derive rice cropland layers is to manually digitize optical (near-infrared) satellite imagery $[10,11]$. This process provides a data product with an internal and external quality assurance. However, the process is time-consuming, expensive, labor-intensive and best suited for small scale applications, whereas over large regions classification results may not always be directly comparable because the results achieved by different experts may differ. One rice cropland layer produced in this way is part of the CORINE land cover (CLC) product that has a resolution of $100 \mathrm{~m}$ and will be updated after every $4-6$ years. This does not meet the requirements of many users who prefer having annual rice cropland maps with higher spatial resolution (e.g., $20 \mathrm{~m}$ ).

Day-night and weather independent data acquisition capabilities of SAR sensors have made them attractive for monitoring land surface dynamics. With the launch of Sentinel-1A/B (a C-band space-borne SAR sensor), data with much improved spatio-temporal sampling characterizations have become available (over Europe $20 \mathrm{~m}$ spatial resolution images are acquired every three days). Furthermore, the free and open data policy adopted by the Copernicus program will make the data accessible to a large user community, and will help accelerating the progress in geophysical research in general and paddy rice cropland mapping in specific.

There is a long history of rice cropland area mapping with SAR sensor imagery [12-16]. Multi-temporal SAR data can be used to retrieve the rice growing cycle based on the temporal variations in the SAR backscatter $\left(\sigma^{\circ}(\mathrm{dB})\right)$ signal $[12,16,17]$. The annual variation in $\sigma^{\circ}(\mathrm{dB})$ from rice fields is higher than any other agricultural crop [13]. In this particular application domain, a substantial number of studies have already been reported in the literature. Most of them used medium resolution SAR data over test sites, mostly located in India [18], Bangladesh [19], Thailand [20], China [21-23], Vietnam [14-16,24] and also a few in Europe [25,26]. High spatial resolution SAR data $(\leq 20 \mathrm{~m})$ have been investigated over a fewer study sites because of the difficulty of collecting dense and long-enough image time series [27-30].

Time series analysis of SAR backscatter values is the most common data analysis approach used for paddy rice identification. Both single and multi-polarization SAR data have been used for rice monitoring and the discrimination of different growth stages [14,31]. In this approach, C-band SAR sensor have been the most attractive data source for rice mapping at regional or continental scale because data from other SAR sensors is hampered either by limited spatial coverage (e.g., TerraSAR-X) or longer revisit time (e.g., ALOS PALSAR).

Several investigations $[14,32]$ demonstrated that the C-band like-polarized ratio $(\mathrm{HH} / \mathrm{VV})$ is a useful parameter for mapping and monitoring rice cropland. Wu et al. (2011) reported that the HH/VV ratio was best for discriminating rice from bananas, forest, and water [33]. However, Schmitt and Brisco (2013) reported that the HH/VV combination produced a significantly lower accuracy than the combination of $\mathrm{HH} / \mathrm{HV}$ and $\mathrm{VV} / \mathrm{VH}$ [34]. The backscatter coefficients of cross-polarized data have a significant correlation with the development of rice plants [33,35]. Schmitt and Brisco (2013) also found that the cross-polarized data gave the best relationship with rice age after transplantation. Due to the improved spatio-temporal resolution and ability to acquire data in different polarizations (VV, $\mathrm{VH}$ ), S-1 is expected to improve the accuracy of rice cropland monitoring and mapping applications.

Literature review suggests that most of the studies have been limited to map paddy rice from C-band SAR data either by using single polarization $(\mathrm{HH})$ or a combination of different polarizations $(\mathrm{HH} / \mathrm{VV}, \mathrm{HH} / \mathrm{HV}$ or VV/VH). However, only a few of them have investigated dense VH backscatter time series in order to have a better understanding of the SAR response to growth stages of the rice fields. Furthermore, to our knowledge, no work using real S-1 data for paddy rice mapping in the Mediterranean region has been published yet.

The goal of this research is to evaluate the potential and transferability of a phenology-based classification strategy developed by Nguyen et al. (2016) [36] over a regional test site in the Mekong 
Delta to a continental scale (Mediterranean region). To achieve this objective, we used a dense time series stack of S-1 backscatter data as input to map rice paddy area at fine spatial scale over eight study sites in six European countries.

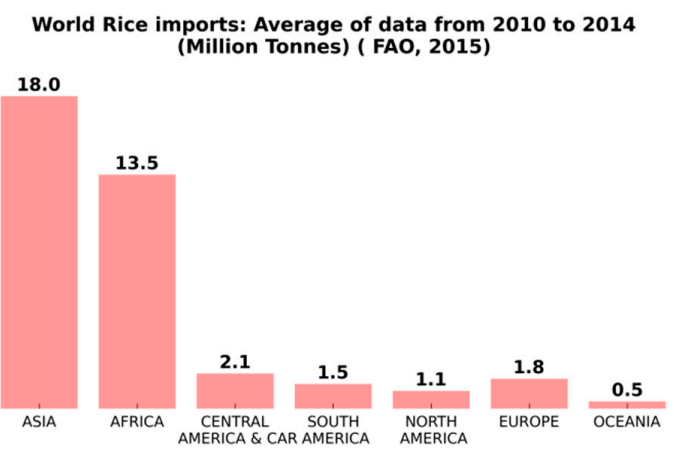

(a)

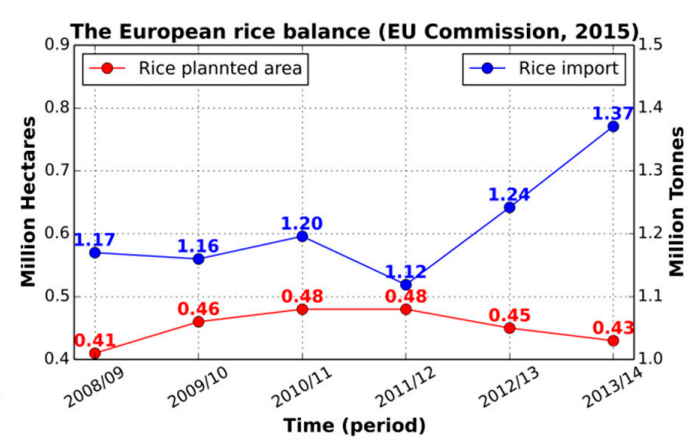

(b)

Figure 1. (a) Global rice imports, average of data for 2010 to 2014 [1]; and (b) the EU rice balance for 2008 to 2013 [37].

\section{Study Area and Materials}

\subsection{Study Sites Characteristics}

In the European Union (EU) the total area of cultivated rice is about 430,000 hectares. The growing areas are mostly located in the Mediterranean countries [1] (Figure 2), where the summer seasons are warm and dry. The normal growing season is either from April/May to September/October or from May to October/November depending on the temperature. Italy and Spain are the top rice producer EU member countries followed by Greece, Portugal and France [37].

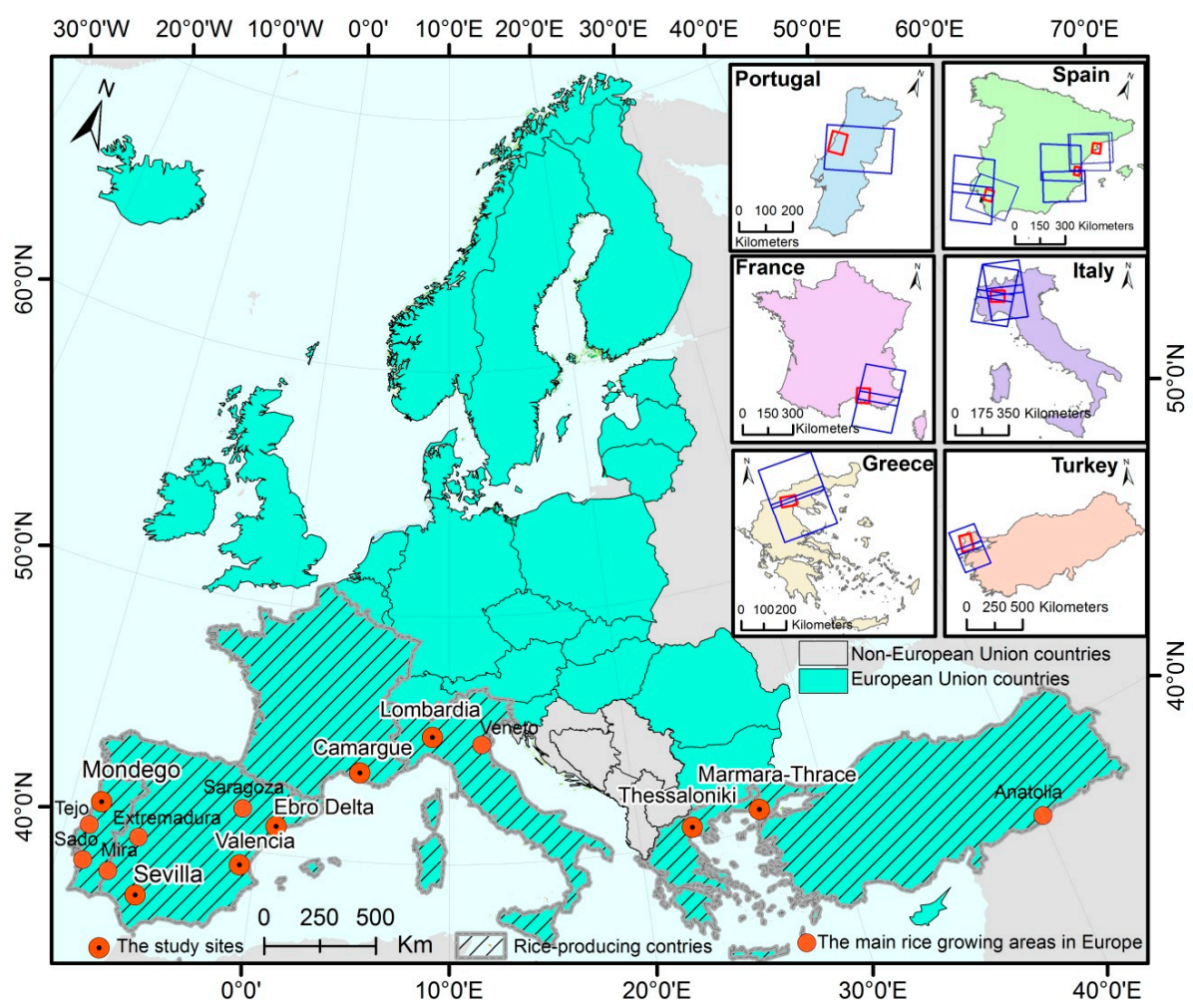

Figure 2. Study sites (red) and spatial extent of the used S-1 scenes (blue). 
Rice varieties grown in Europe mostly belong to the Japonica (70\%) and Indica (30\%) species group. The recent evolution of Japonica and Indica areas (in hectares) in the EU member States is shown in Figure 3. Rice is mostly grown in congregated areas such as in the Po valley in Italy, the Rhône delta in France, and the Thessaloniki area in Greece. In Spain, rice cultivation is more scattered; rice growing areas are found in the Aragon region, the Guadalquivir valley, the Ebro delta and Valencia Albufera [38]. In Portugal, rice cultivation area is concentrated mainly in three regions: the Tagus and Sorraia valleys, the Mondego, and the Sado and Caia river valleys [39,40]. In Turkey, the most productive regions are Thrace and Marmara, which are producing $10-15 \%$ of the total national rice production.

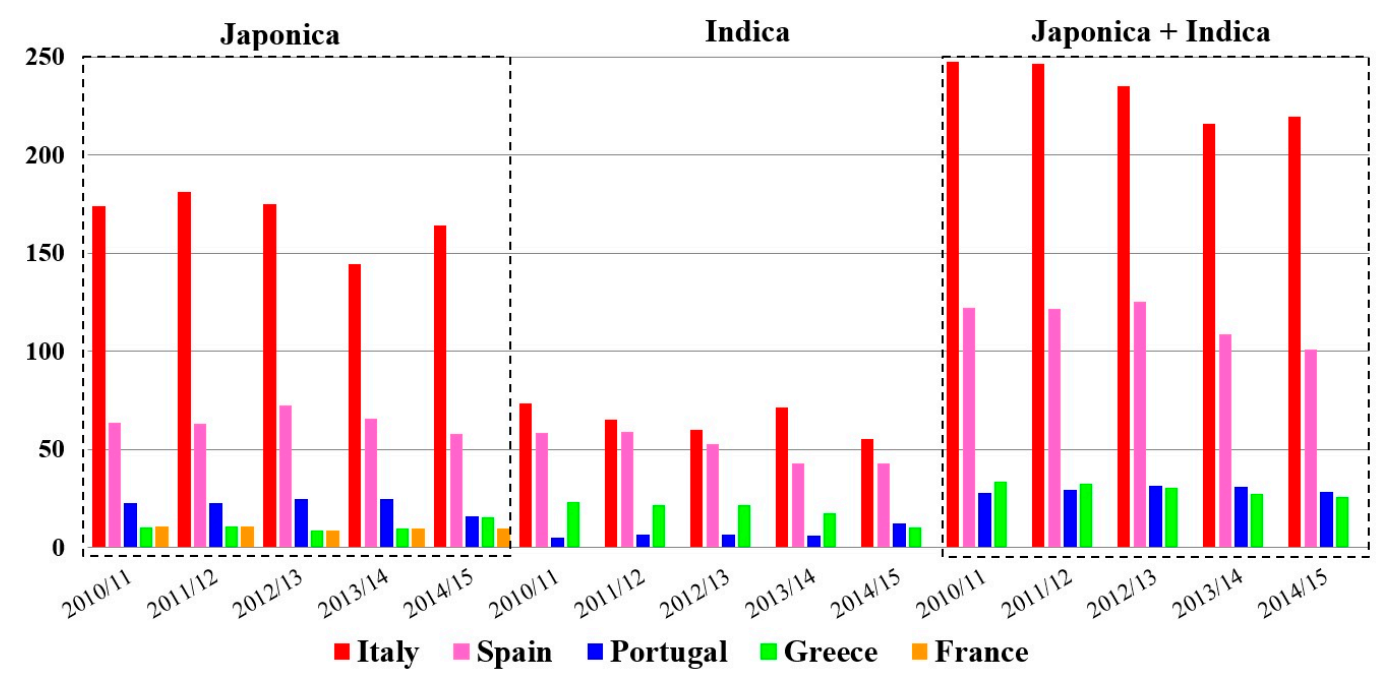

Figure 3. Rice varieties areas in the EU member states [37].

Rice planting in Europe involves direct seeding into flooded soil (water seeding) or dry soil (dry seeding). With both the farming methods, the floodwater is maintained until the harvest season. Water is drained several times from the field prior to harvesting so that the fields can be dried and harvesting equipment can pass through. Fields are also drained for early foliar herbicide treatments, then re-flooded within few days. The drainage period allows certain weed species to germinate in the aerobic environment (Figure 4).

\subsection{Materials}

\subsubsection{Sentinel 1A Data}

For this study, we accessed archived Interferometric Wide Swath (IW) mode S-1 data acquired during the rice crop growing cycle in 2015, from April to early November to completely cover every test site. The S-1A SAR IW mode acquisitions come from eight different tracks, whereas each test site is covered by the same track (Figure 2). The details for each test site regarding data acquisition, location, date, path and range of incidence angle are shown in Figure 4. All the images were obtained from ESA as standard Level 1 GRD (ground-range detected) high resolution images. Only the S-1 IW acquisitions with $\mathrm{VH}$ polarization were selected for rice cropland classification.

\subsubsection{Optical Data and Ancillary Data}

For the study sites in France, and Italy, multi-temporal Spot 5 (10 m spatial resolution) for the year 2015 were downloaded from the SPOT website [41]. These optical datasets were used to produce reference classification maps for validating the S-1 rice maps. Rice cropland area-a vector dataset with a minimum mapping unit (MMU) of 1 hectare-over Seville in Spain for the year 2015 has been obtained from the Institute of Statistics and Cartography of Andalusia's website [42] Two others vector 
dataset of rice cropland area-over Valencia in Spain and Thessaloniki in Greece for the year 2015 were retrieved from the ERMES (An Earth Observation Model Based Rice Information Service)'s website [43] Google Earth imagery and Sentinel-2 [44] optical data were used to produce reference data for the rest of study areas. In addition to this, the European CORINE land cover (CLC 2012) product was also used for comparing classification results across all European test sites in a consistent manner. The data set is not as detailed and accurate as the other two datasets. However, it is the only available reference datasets covering all our study regions. Figure 5 shows the land cover composition over the eight selected test sites in 2012. Rice cropland is the most common land cover in Lombardia, Italy with $33.6 \%$, followed in Ebro, Spain (18.8\%) in Valencia, Spain (12.4\%), and only 2.3\% of rice cropland in Mondego, Portugal. Inland water makes up over $10 \%$ of the total land covers in Camargue, France and below $1.5 \%$ for the others. It is the same for wetland class, e.g., $7 \%$ in Camargue, France, and below $2 \%$ for the others.

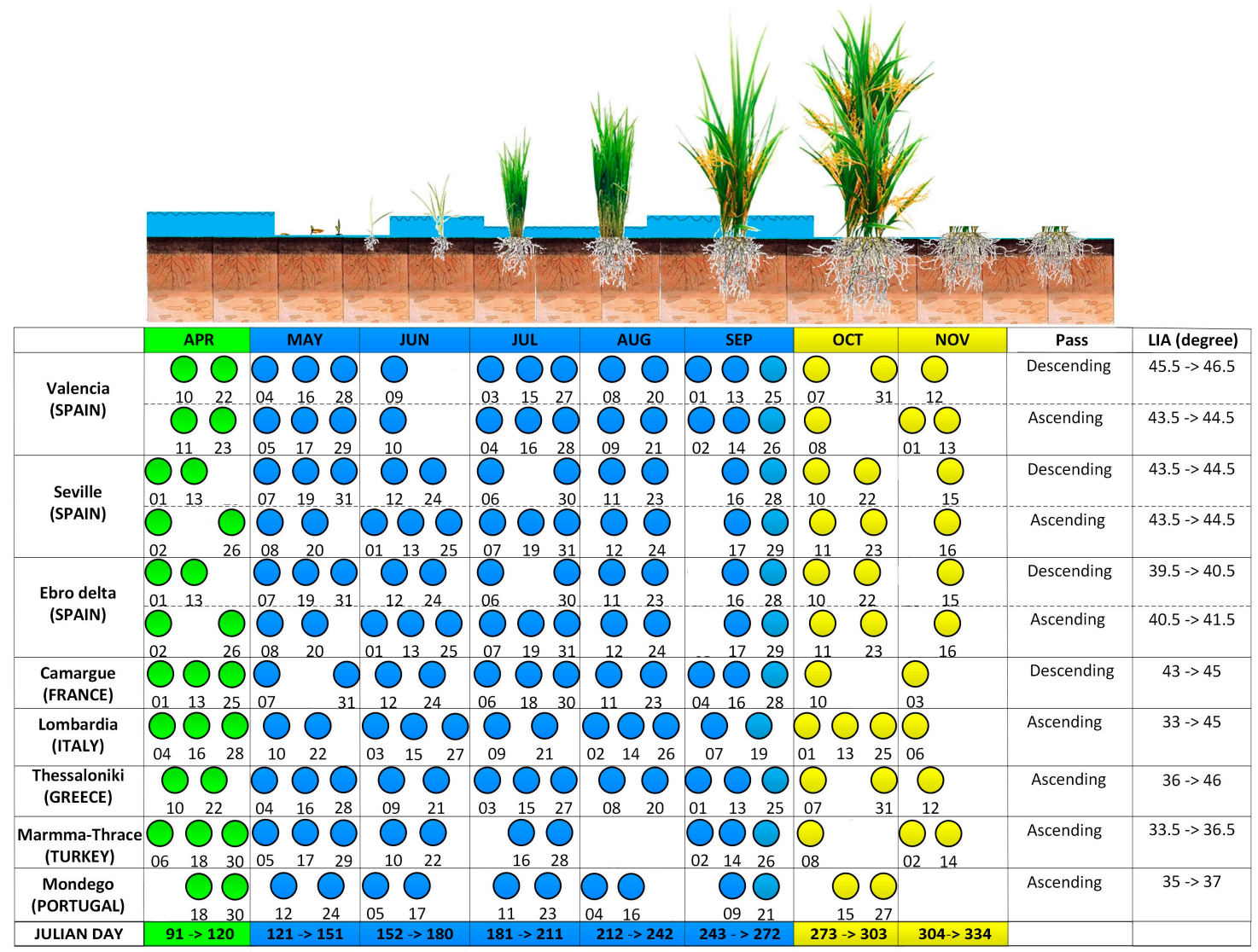

Planting $\bigcirc$ Mid-Season $\bigcirc$ Harvest $\bigcirc$ L1 GRD-HD data available LLA: Local Incidence Angle

Figure 4. Growing season of paddy rice crop and the available S-1A SAR scenes over eight selected test sites. 

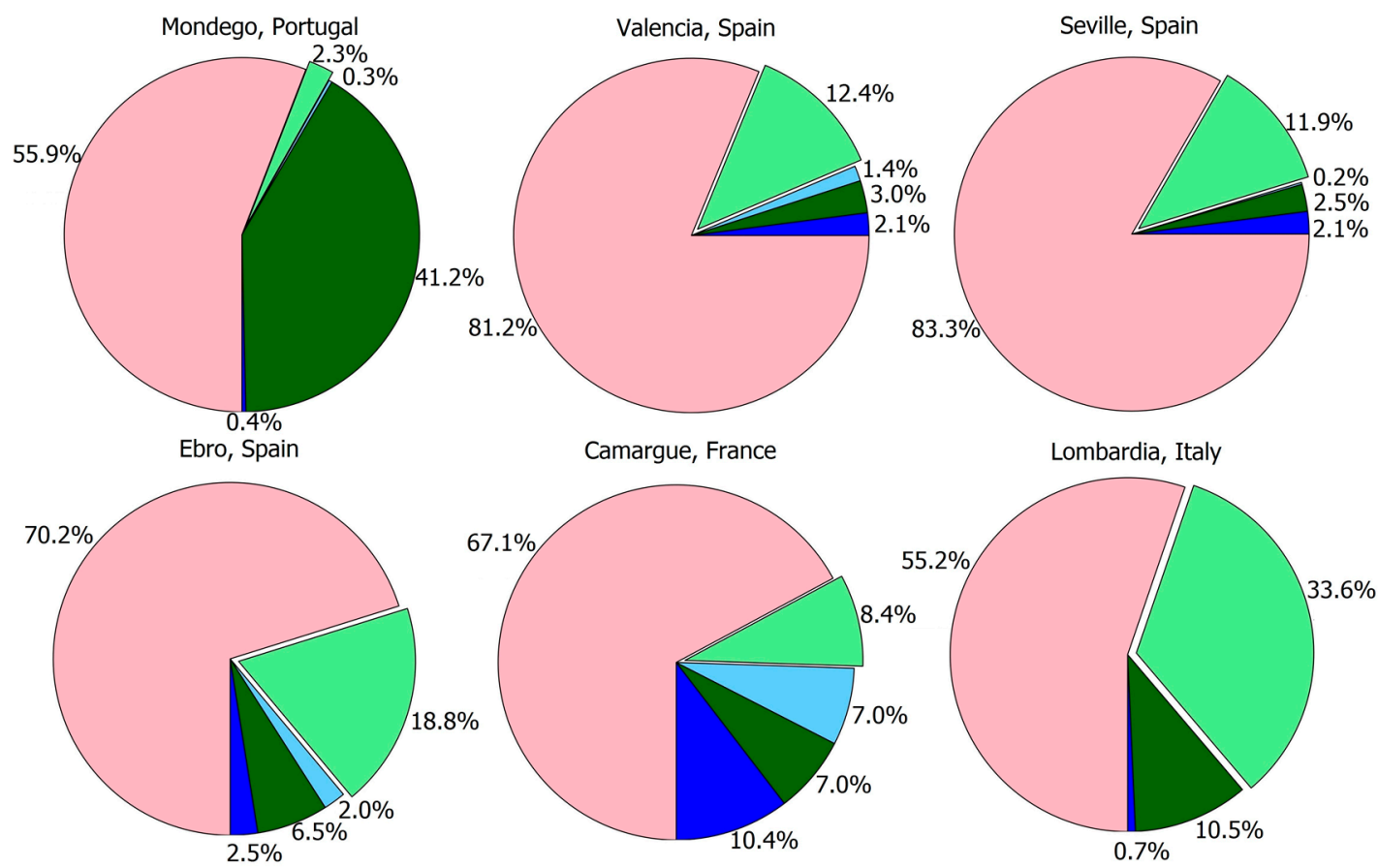

Camargue, France
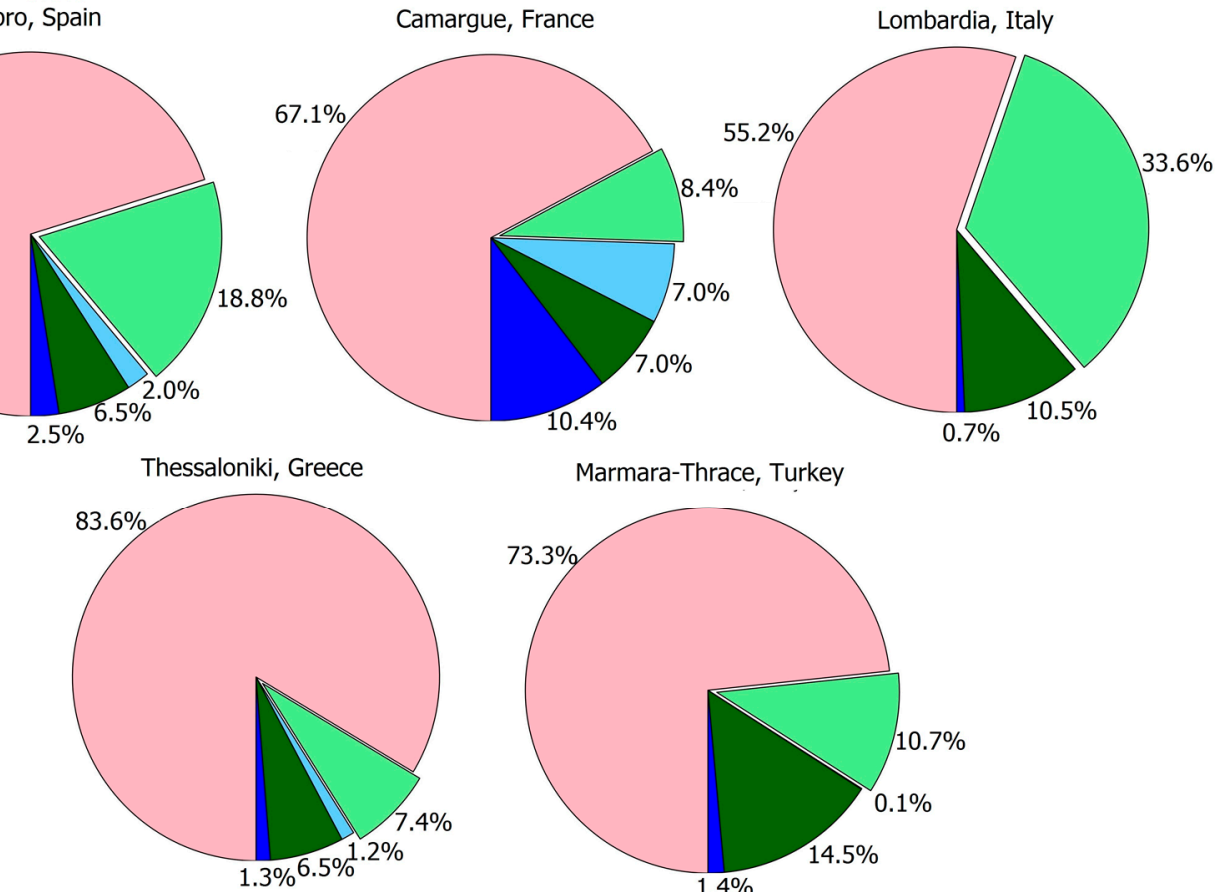

Marmara-Thrace, Turkey

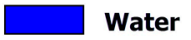

Forest

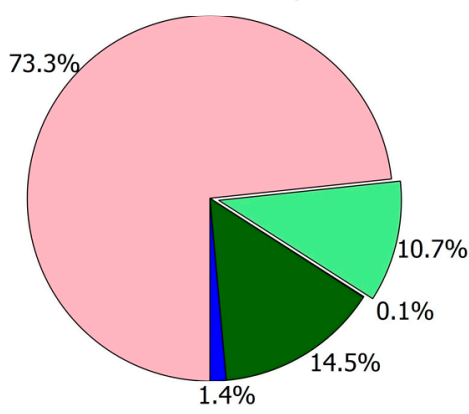

Wetland

Rice

Other land

Figure 5. Relative contribution of harmonized land-cover categories in eight selected test sites.

\section{Methodology}

The time series algorithm used in this study was introduced by Nguyen et al. [36]. It consists of six steps as illustrated in Figure 6: (1) S-1A pre-processing; (2) segmentation to extract the potential rice areas $\left(\sigma^{\circ} \rightarrow \sigma^{\circ}\right.$ potential); (3) time-series smoothing with a Gaussian moving window filter ( $\sigma^{\circ}$ potential $\rightarrow \sigma^{\circ}$ potential_smooth); (4) vegetation phenology parameters extraction $\left(\sigma^{\circ}\right.$ potential_smooth $\rightarrow$ DoS (Date of Start Season), DoM (Date of Maximum backscatter), LoS (Length of Season)); (5) classification using a knowledge-based decision-tree approach; and (6) accuracy assessment based on reference data.

\subsection{Pre-Processing}

All the selected S-1 SAR IW images were pre-processed (orbit correction, radiometric calibration, resampling and geocoding) using ESA's Sentinel-1 Toolbox. The geocoding step involved a Range Doppler Terrain correction algorithm that uses the elevation data from the 1 arc-second DEM product from the Shuttle Radar Topography Mission (SRTM) and POD orbit state vectors provided by ESA. Notice that precise orbits files (POD) are produced few weeks after the acquisition and they are automatically downloaded from ESA website [45]. In this process, data are resampled and geo-coded to a grid of $10 \mathrm{~m}$ spacing preserving the $20 \mathrm{~m}$ spatial resolution. 


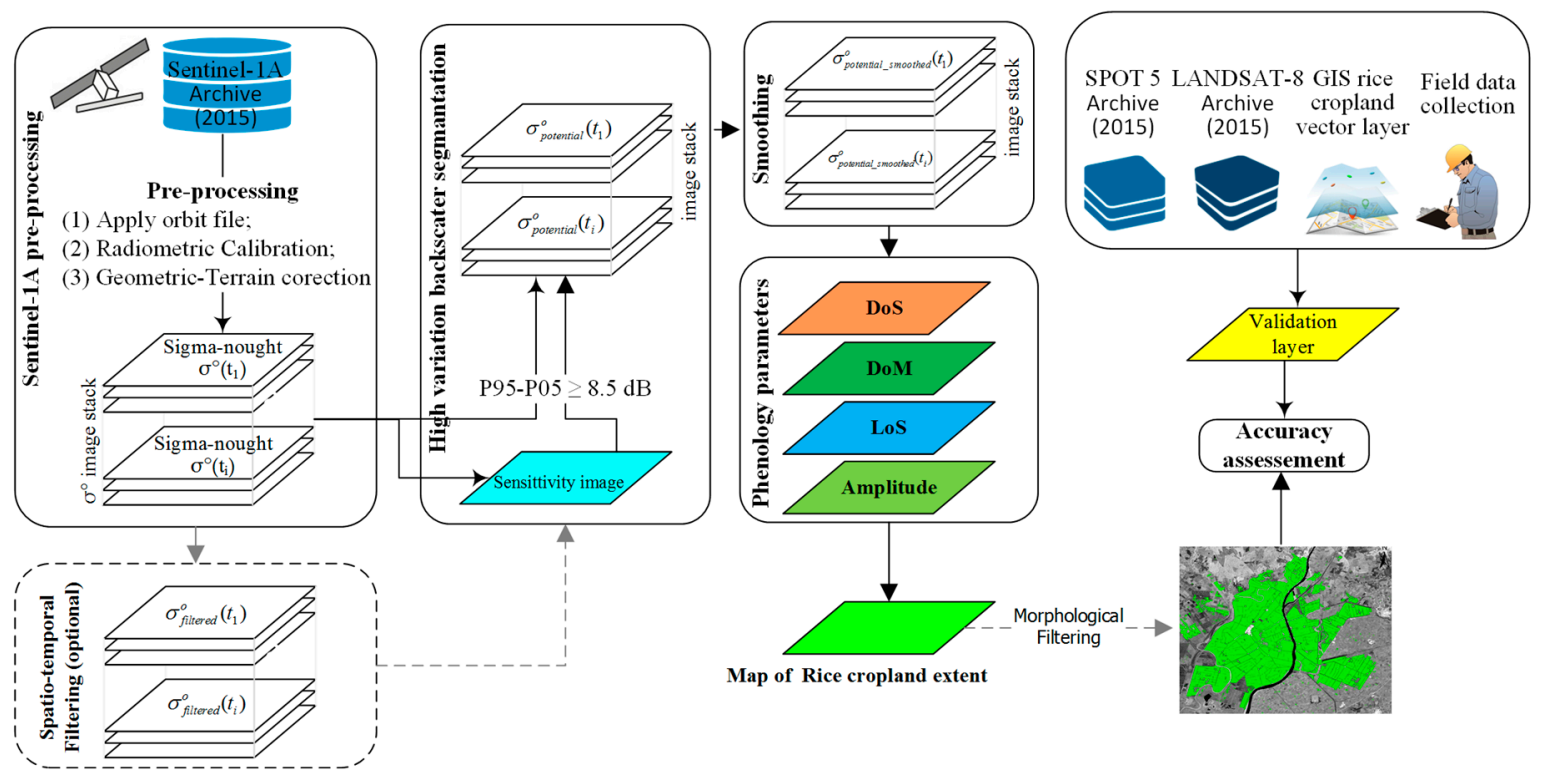

Figure 6. Systematic workflow of S-1 SAR (VH polarization) data processing, rice area classification and validation.

\subsection{Identification of Potential Rice Pixels}

For the identification of potential rice growing areas, our approach is to threshold the dynamic range backscatter image to identify image pixels that change more than the defined threshold value (dB). Threshold value selection depends on the nature and expected changes in the magnitude of VH backscatter and the SAR geometry (e.g., incidence angle). A generalized threshold for the rice fields can only be determined if the optimum SAR data acquisition is guaranteed (e.g., SAR observations are available in the flooded and vegetative stages). Otherwise, the threshold must be optimized considering the data acquisition and the constraints of local crop calendar. S-1A provides at least one acquisition after every 12 days over the selected study sites (see Figure 4); after the launch of S-1B the temporal sampling was reduced to 5-6 days. Based on the visual interpretation of optical imagery for the selected period and expert knowledge acquired from the ancillary data, a threshold of $8.5 \mathrm{~dB}$ was used to extract the potential rice pixels referred to as $\sigma_{V H_{-} \text {potential }}^{o}$.

Figure 7 (first column) shows sensitivity images based on dry reference (P05) and wet reference (P95) images for all study areas, and the results of applying thresholds of $8,8.5$ and $9 \mathrm{~dB}$ to these images are illustrated in following columns of the Figure 7. The CLC 2012 map is used to indicate the compartment boundaries, and pixels exhibiting change below and upper the threshold $(8.5 \mathrm{~dB})$ are classified as potential rice cropland areas. Combining Figure 6 with Figure 7 suggests a threshold on sensitivity of $8.5 \mathrm{~dB}$ to extract the potential rice cropland pixels. Lowering the threshold to 8.0 $\mathrm{dB}$ increases area outside the potential rice cropland areas in all the study sites leads to computation time increases. Raising the threshold to $9.0 \mathrm{~dB}$ decreases the potential rice cropland areas may leads to numerous rice pixels are omitted. Thus $8.5 \mathrm{~dB}$ seems the better choice as long as we accept that physically, processing time, as well as classification precision. With this threshold, the majority of the rice cultivated areas are correctly picked out in all data sets. From the basic concept of the approach, it is clear that classification error will occur for the rice pixels whose variation is less than the selected threshold. Different of farming activities during the growing season (rice varieties, water level in the fields, density of rice plants in the fields), SAR acquisitions period may give rise to this type of misclassification. 
Mondego (Portugal)

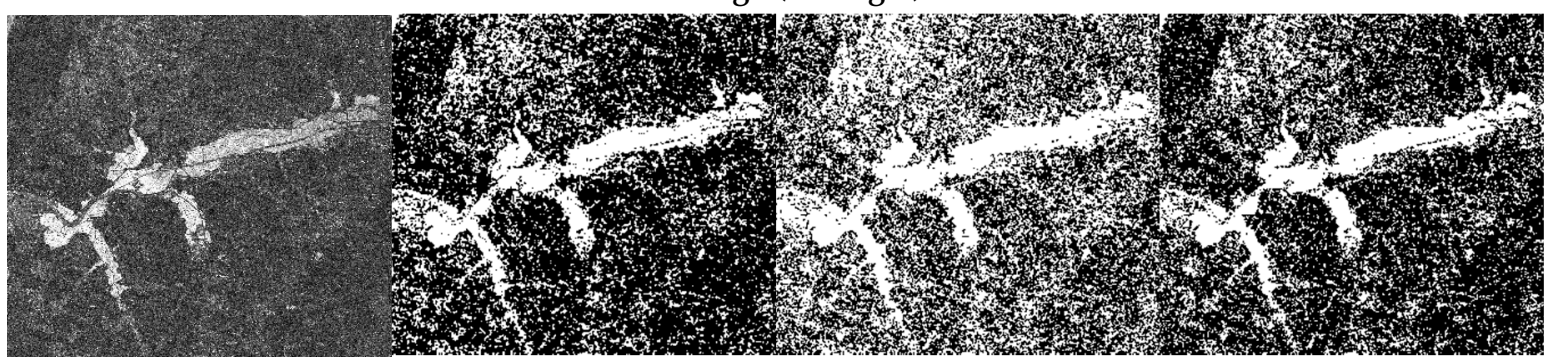

Sensitivity image

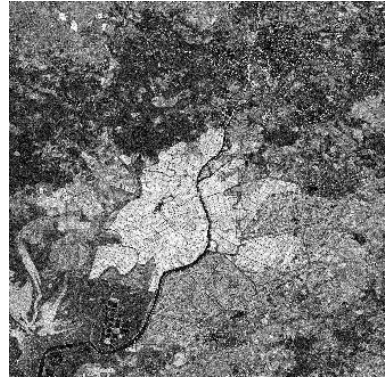

Sensitivity image

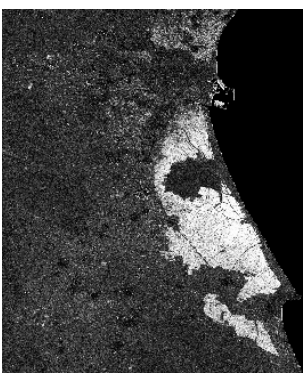

Sensitivity image

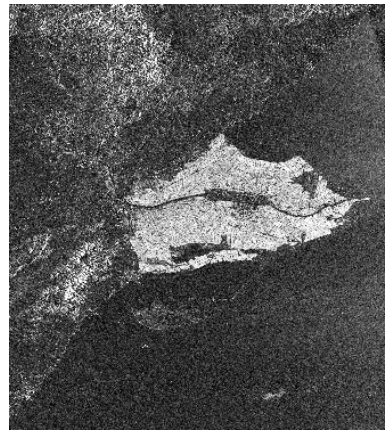

Sensitivity image $\geq 8.0 \mathrm{~dB}$

Seville (Spain)

$\geq 8.5 \mathrm{~dB}$

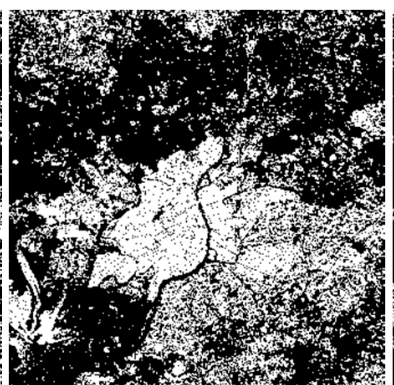

$\geq 8.5 \mathrm{~dB}$

Valencia (Spain)

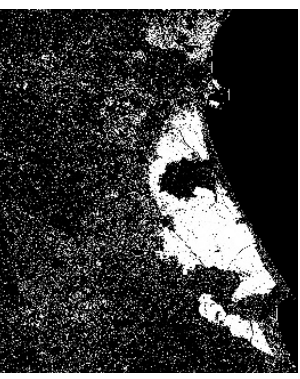

$\geq 8.0 \mathrm{~dB}$

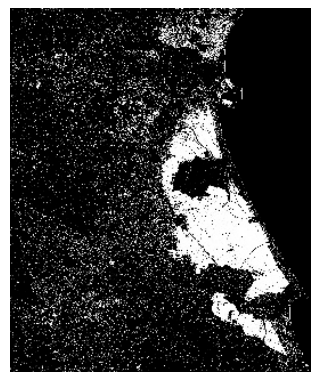

$\geq 8.5 \mathrm{~dB}$

Ebro delta (Spain)

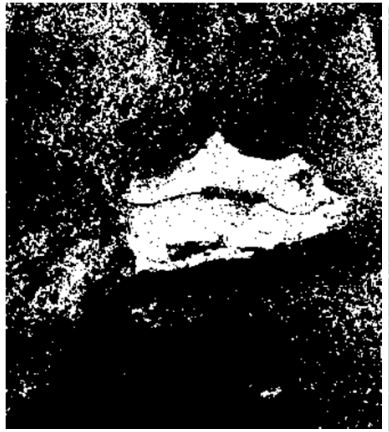

$\geq 8.0 \mathrm{~dB}$

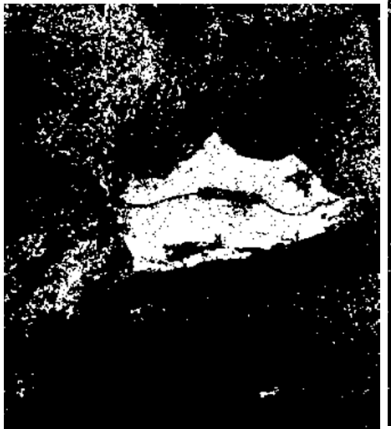

$\geq 8.5 \mathrm{~dB}$

$\geq 9.0 \mathrm{~dB}$

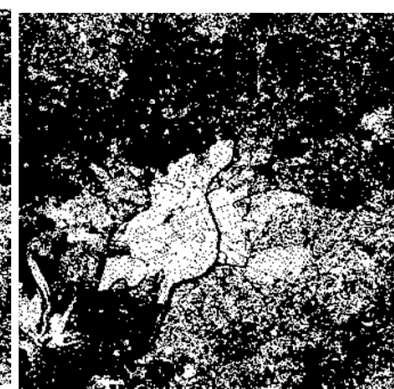

$\geq 9.0 \mathrm{~dB}$

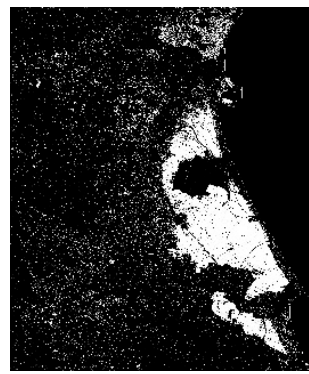

$\geq 9.0 \mathrm{~dB}$

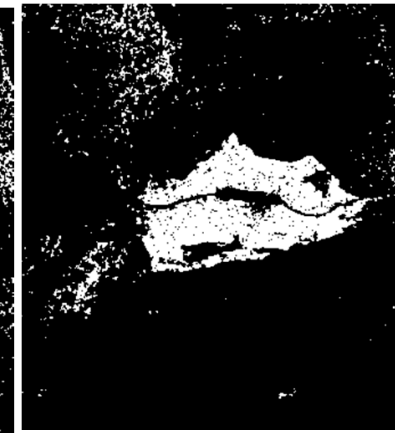

$\geq 9.0 \mathrm{~dB}$

Figure 7. Cont. 


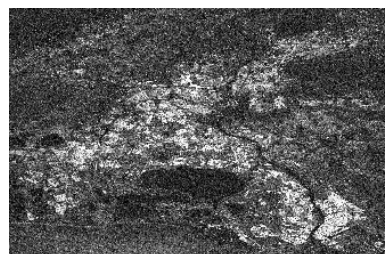

Sensitivity image

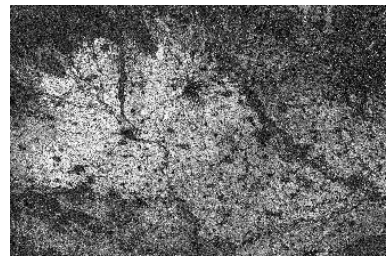

Sensitivity image

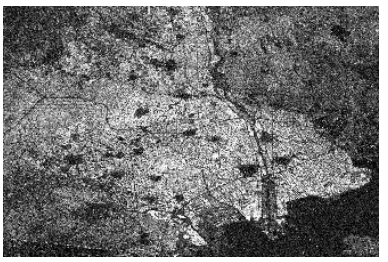

Sensitivity image

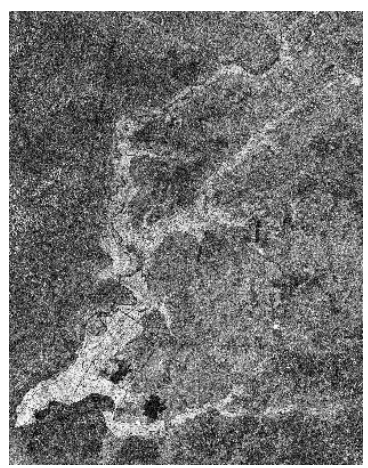

Sensitivity image

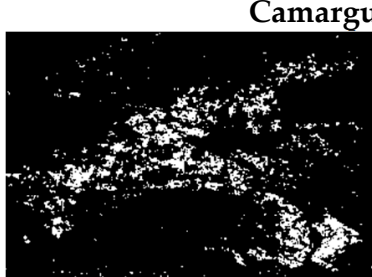

$\geq 8.0 \mathrm{~dB}$

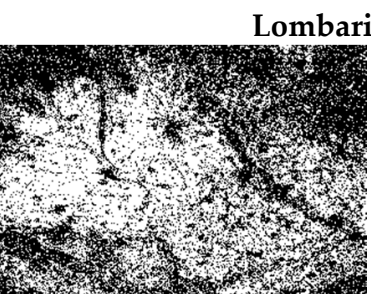

$\geq 8.0 \mathrm{~dB}$

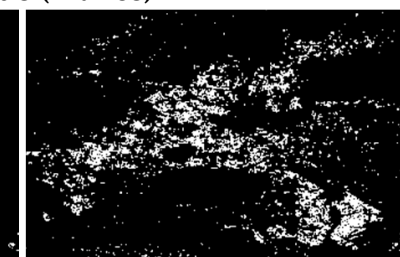

$\geq 8.5 \mathrm{~dB}$

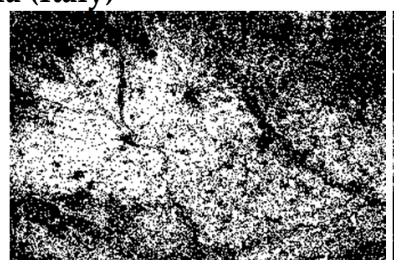

$\geq 8.5 \mathrm{~dB}$

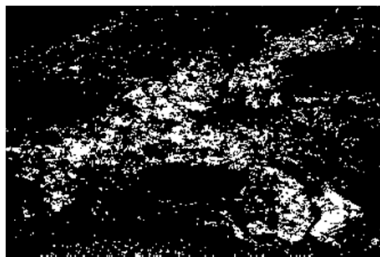

$\geq 9.0 \mathrm{~dB}$

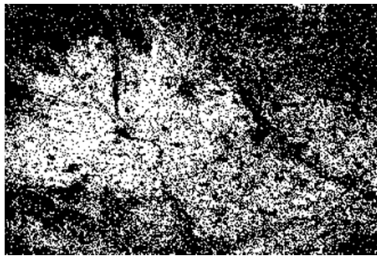

$\geq 9.0 \mathrm{~dB}$

Thessaloniki (Greece)

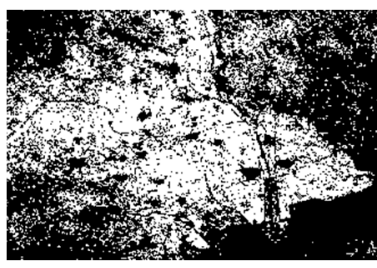

$\geq 8.0 \mathrm{~dB}$

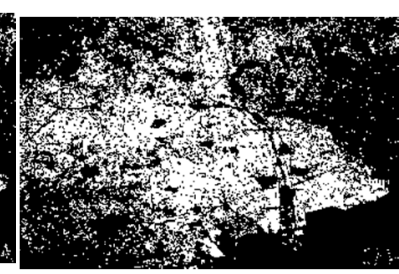

$\geq 8.5 \mathrm{~dB}$

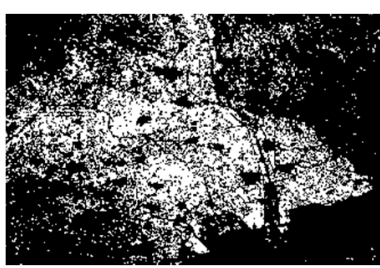

$\geq 9.0 \mathrm{~dB}$

Marmma-Thrace (Turkey)

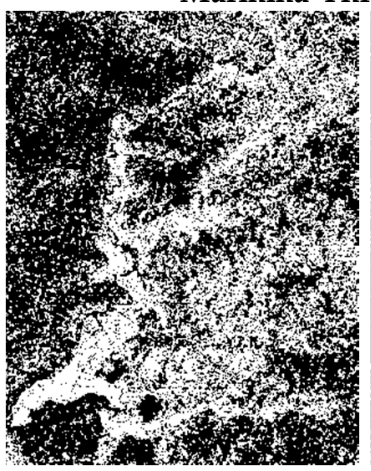

$\geq 8.0 \mathrm{~dB}$

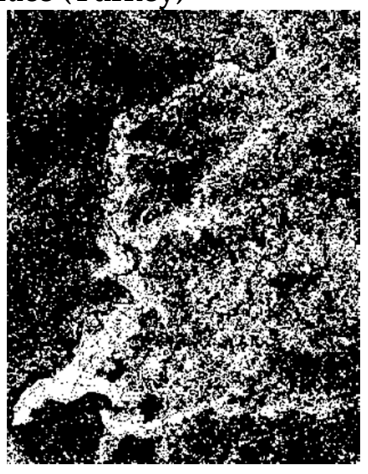

$\geq 8.5 \mathrm{~dB}$

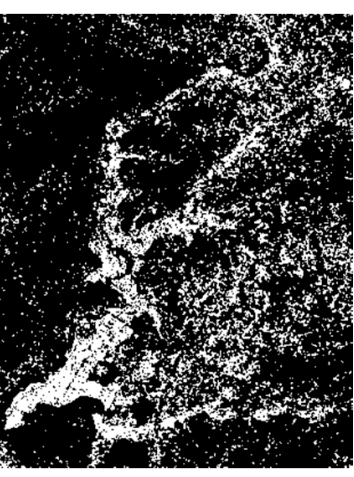

$\geq 9.0 \mathrm{~dB}$

Figure 7. Sensitivity images and potential rice cropland area extent results using different thresholds.

\subsection{Time Series Filtering}

Filtering the backscatter time series has the purpose of reducing the short-term influence of environmental conditions and noise inherent in the S-1 data due to speckle and other noise-like influences. The processed output is a smoothed backscatter signal $\left(\sigma_{V H_{\text {potential_smooth }}}\right)$, which will be used for the extraction of different phenological stages of rice (e.g., a start of the season, heading time, and length of season). For the temporal filtering of the $\sigma_{V H}^{o}$ potential time series a Gaussian smoothing filter (with the standard deviation of $3 \mathrm{~dB}$ for the kernel) was used. A detailed investigation on the selection of kernels with different standard deviation was already reported by Nguyen, Wagner et al. 2015 [16]. Moreover, in order to discriminate the rice pixels from the other land cover classes we have empirically defined a list of three more static thresholds based on the $\sigma_{V H_{\text {potential_smooth }}^{o}}$ values. 


\subsection{Extraction of Vegetation Phenology Parameters}

For this step, we calculated three phenological indicators, namely, date of beginning of season (DoS), date of maximum backscatter (DoM), and Length of the season (LoS). This allows to delineating the areas as "rice paddy", and all other areas were placed in a generalized "non-rice" class. These parameters, introduced by [37], are summarized in Table 1.

Table 1. Phenological parameters for the rule-based classification.

\begin{tabular}{|c|c|}
\hline Parameters & Definition and Explanation \\
\hline DoS & $\begin{array}{l}\text { During the growing season, the date of the beginning of season is defined as the first local } \\
\text { minima in } \sigma_{V H_{\text {potentia_smooth }}^{o}} \text { time-series. }\end{array}$ \\
\hline DoM & 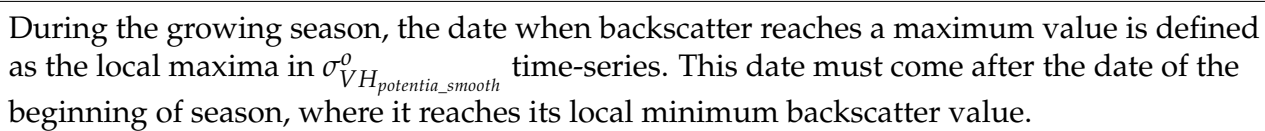 \\
\hline LoS & The length of the season is defined as the number of days difference between DoM and DoS. \\
\hline
\end{tabular}

\subsection{Rice Paddy Identification}

Due to the high temporal variability in the SAR backscatter signal across the different study sites, the raw output from the thresholding of phenological profiles contained some noisy pixels. This implies that most fields were not fully classified as rice and non-rice class at the pixel level. Therefore, we constrained the minimum mapping unit to the average farm size in the Mediterranean region, which is $1 / 4$ hectares. This means that no polygon was composed of fewer than $25 \mathrm{~S}-1$ pixels ( $20 \mathrm{~m}$ spatial resolution, $10 \mathrm{~m}$ pixel spacing). We implemented this through a post-classification processing step, whereas a majority/minority analysis with the window size of $5 \times 5$ pixels was applied to remove the small pixel groups in order to obtain refined classification results.

\subsection{Accuracy Assessment}

For validation and evaluation of classification results, standard accuracy assessment measures were used, i.e., kappa coefficient, overall accuracy, omission error, and commission error. Rice cropland vector layer 2015 for study site in Spain (Seville), rice cropland maps created through interpretation of SPOT-5 data for three study sites in Spain (Valencia), Italy, and France; rice cropland raster layers 2006 from CLC 2006 for Marmara-Thrace, Turkey; and rice cropland raster layers from CLC 2012 for all study sites were used.

\section{Results and Discussion}

\subsection{Temporal Rice Backscatter Signature from Sentinel-1 SAR Data}

Seasonal VH time series are shown in Figure 8a-h, for Mondego (Portugal), Seville (Spain), Valencia (Spain), Ebro delta (Spain), Camargue (France), Lombaria (Italy), Thessaloniki (Greece) and Marmma-Thrace (Turkey), respectively. In addition, Figure 8a-h also shows the results of smooth backscatter profiles (magenta color), and the date of maximum and minimum backscatter values for the selected rice fields (represented by the red and blue dots, respectively). To complement this analysis, Figure 9 shows the VH backscattering coefficients and false color composites of the study sites.

Figure 9 (column 4 ) shows the color composites, which are created by using the multi-temporal SAR acquisitions in order to highlight the temporal characteristics within the rice fields. The red, blue, and green colors in these figures (Figure 9, column 4) correspond to the images acquired during the flooded/seeding (April/May), heading (August/September) and post harvested (October/November) period, respectively. The blue and dark green color regions in these figures (Figure 9, column 4) indicate the rice cropland areas. At the beginning of the growing season (April-May) the $\sigma_{V H}^{o}$ values 
from the rice fields were very low due to flooding after sowing. Thus, in the early stage of rice crop growth the fields appeared as dark areas in SAR images. This condition corresponds to those scenes that were acquired during the months April and May (see black areas in Figure 9, the first column). In general, during this period the rice fields show low backscatter values, e.g., less than $-20 \mathrm{~dB}$ (for reference, see Figure 8). However, there are several conditions related to the soil preparation and wind speed/direction that must also be considered. Some rice fields require a special tillage, such as furrows, or the presence of low water level in the field for a shorter period due to the diversity in farming activities among different parts of the region. If these furrows are shallow and under light wind conditions, the surface is smooth irrespective of the furrow direction. However, if the furrows are deep, the furrow direction becomes an important factor regarding SAR image acquisition geometry. In case that the deep furrows are nearly parallel to the radar viewing direction, the surface seems smooth in radar image. On the other hand, if the deep furrows are perpendicular to the radar viewing direction, the surface becomes strongly rough, and the signal backscatter becomes very strong. These results are in accordance with Brisco et al. (1991) when evaluating the effect of tillage row direction in relation to the radar's look direction using radar backscattering coefficient from three different radar frequencies [45]. The Sentinel-1 data are also influenced by the incidence angle, whereas the strength of the radar's backscatter signal gradually decreases with the increase of incidence angle. Therefore, backscatter is in general higher over the Marmma-Thrace (Turkey) and Mondego (Portugal) sites, where the incidence angles were $35^{\circ}$ and $36^{\circ}$ compared to the other regions where the incidence angle was about $40^{\circ}$ (Figures 4 and 8 ).

In the second stage (vegetative stage), backscatter value increases as the vegetation grows (e.g., plant size increases), and eventually the SAR images show no significant difference between rice fields and other agricultural fields or vegetated areas (see bright areas in Figure 9, second column). One month to 45 days after the start date of the growing season it reaches the first peak in June/July. Specifically, a simple visual inspection to the $\sigma_{V H}^{o}$ images which were acquired at the end of July (where DoY is around 210, Figure 8a-h)) reveals that the backscatter value has dropped suddenly, despites the fact that vegetation is fully developed. This anomaly is observed for all study sites, except Mondego (Portugal) and Lombaria (Italy). It is clearly illustrated in the case of Seville (Spain) and Valencia (Spain) in the Figure 8. The scale of these changes is quite different for different study sites due to different agricultural practices. Like in other European regions, rice crop in Seville and Valencia (Spain) begins in mid-April with the deep placement of fertilizers under dry conditions. Flooding starts during the first week of May and then the seeds are sown. At the end of June there is a short dry period of ten days [46]. Furthermore, this period is characterized by the increase of the rice plant height and the number and size of tillers that lead to make free space among narrowed or blocked rice stems. As a result, the absence of water from the rice fields will minimize the double bounce effect of SAR signals and this explains the decrease in backscattering values at this stage. For the other regions, throughout the rice cultivation period, water is commonly kept at a depth of $4-8 \mathrm{~cm}$, and drained away 2-3 times during the growing season to improve the crop rooting, reduce the algae growth and to allow application of herbicides. For the reproductive stage (August/September), backscatter values continuously keep increasing until they achieve the maximum value in September. During this period the values of backscattering coefficient vary between the range of $-17 \mathrm{~dB}$ and $-13 \mathrm{~dB}$, which might get influenced by the variations in incidence angle, water level in the fields, cultivation activities or the rice varieties. However, during the ripening phase a slight decrease in SAR backscatter signal is observed. One potential reason for this could be due to the fact that the plants will dry before the harvesting. Normally, rice fields are drained towards the end of August to allow harvesting [47]. 

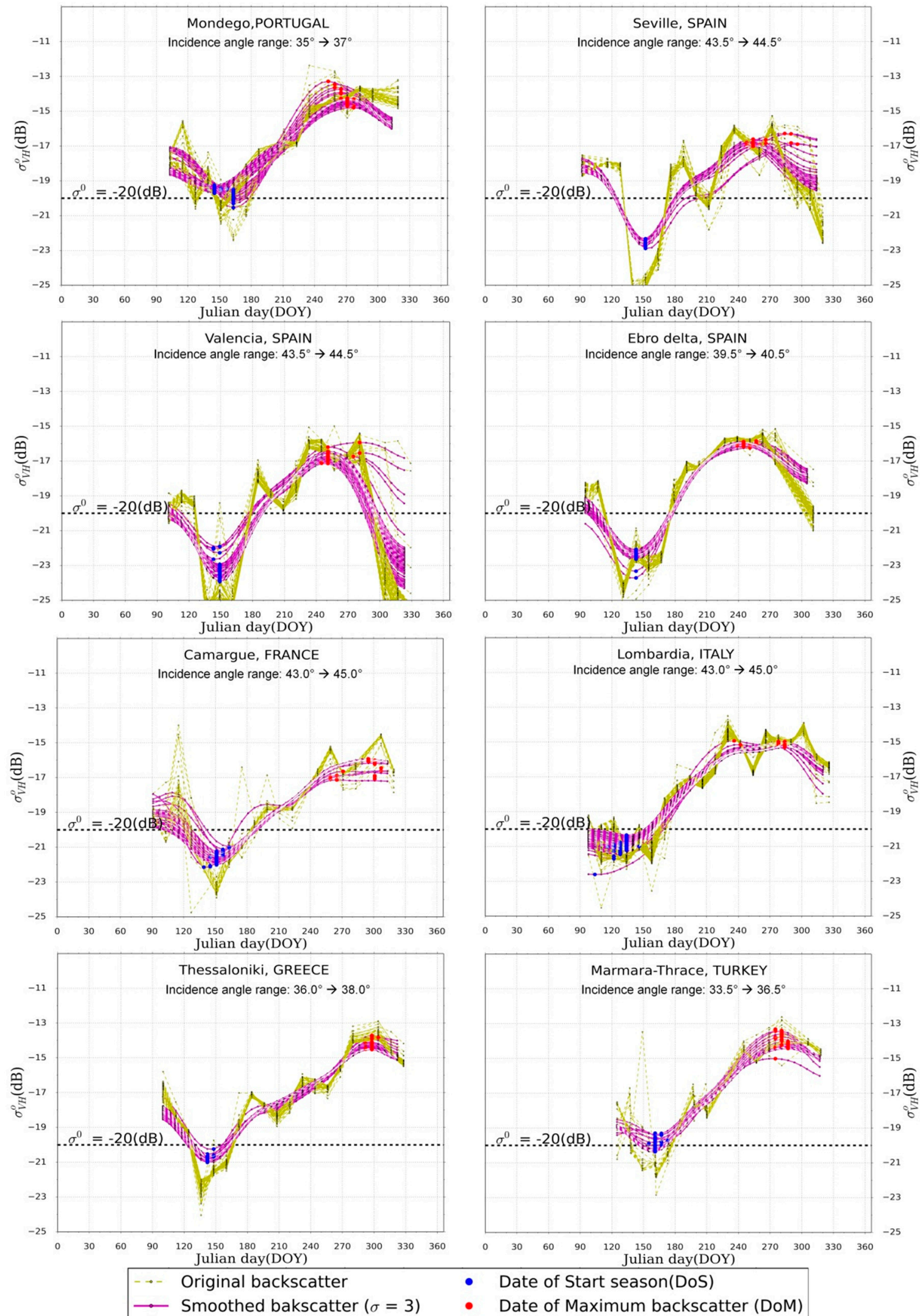

- Date of Start season(DoS)

- Date of Maximum backscatter (DoM)

Figure 8. Temporal evolution of the backscattering coefficients derived from VH polarization (where, $\sigma_{V H}^{o}=-20(\mathrm{~dB})$ is base line). 
Mondego (Portugal)

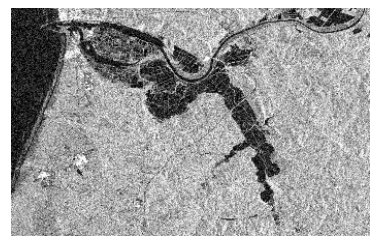

6 May 2015 (R)

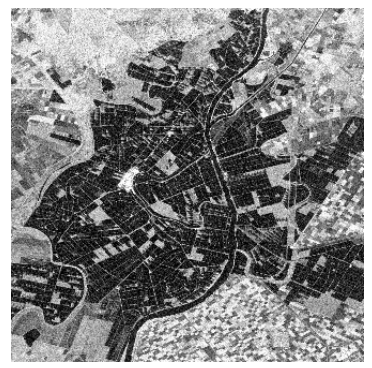

19 May 2015 (R)

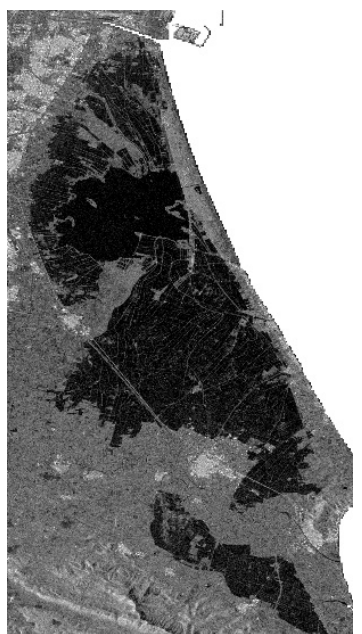

16 May 2015 (R)

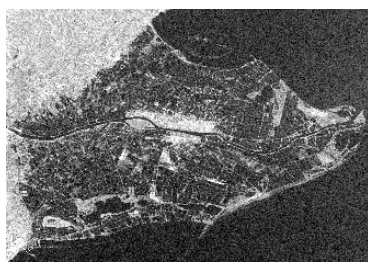

11 May 2015 (R)

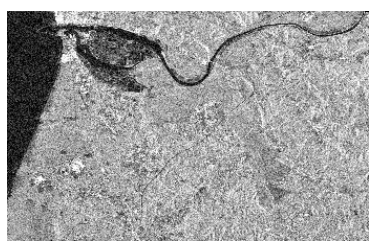

22 August 2015 (G)

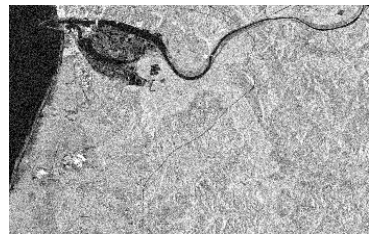

2 November 2015 (B)

Valencia (Spain)
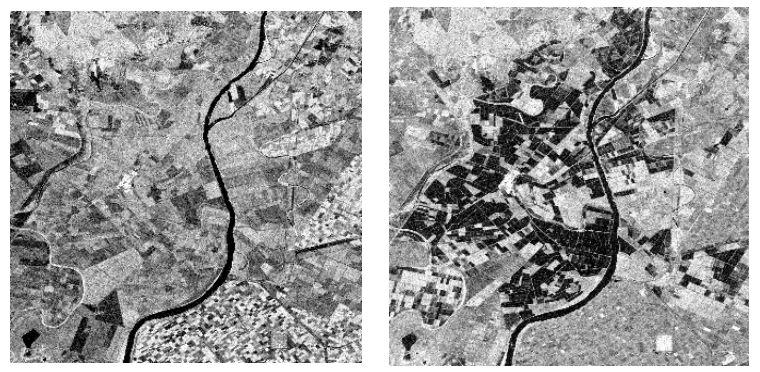

15 November 2015 (B)

23 August 2015 (G)

Seville (Spain)

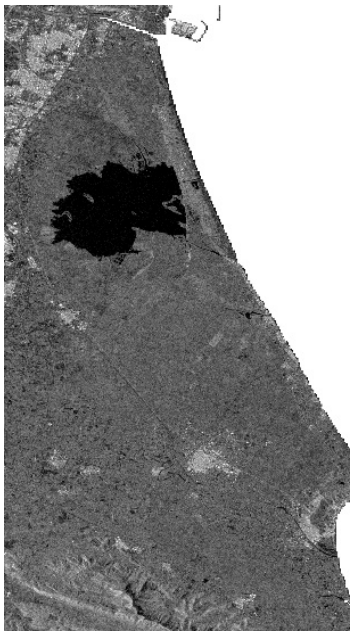

20 August 2015 (G)

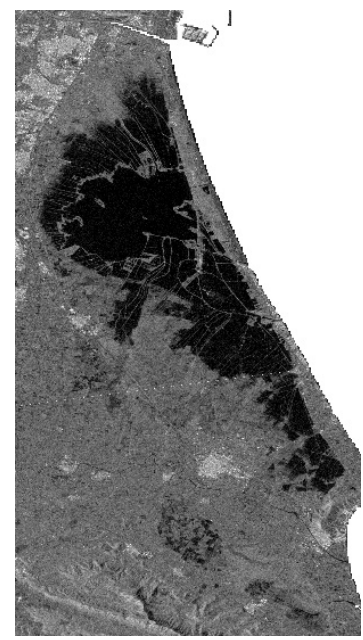

12 November 2015 (B)

Ebro delta (Spain)

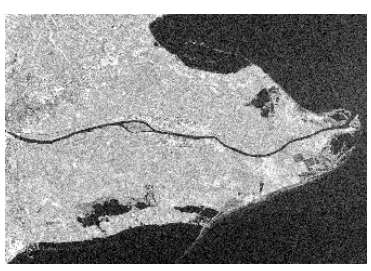

27 August 2015 (G)

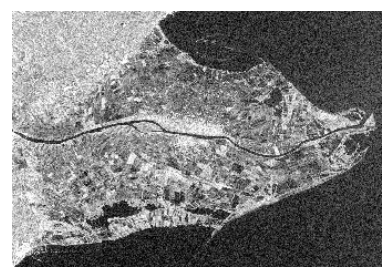

7 November 2015 (B)

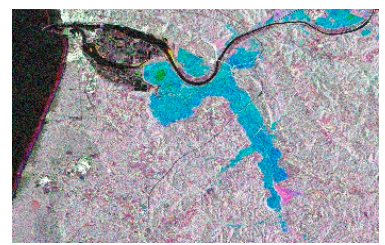

RGB

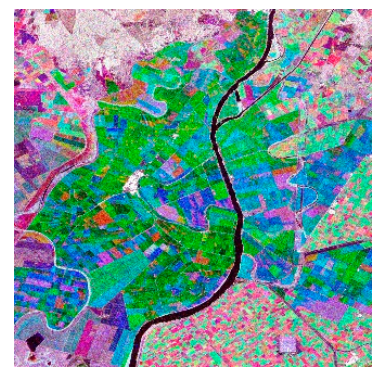

RGB

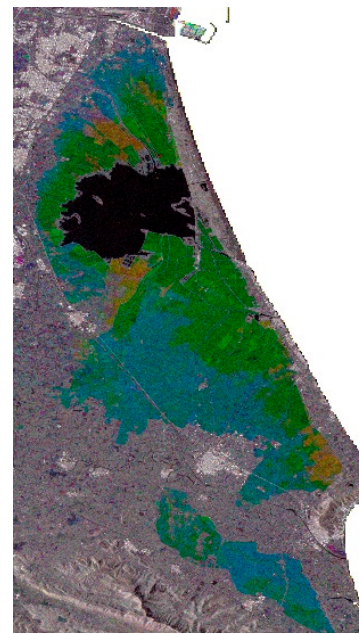

RGB

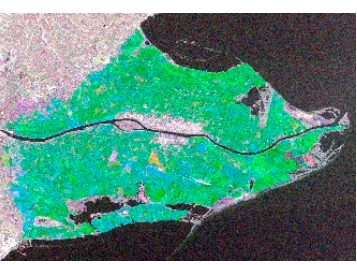

RGB

Figure 9. Cont. 


\section{Camargue (France)}

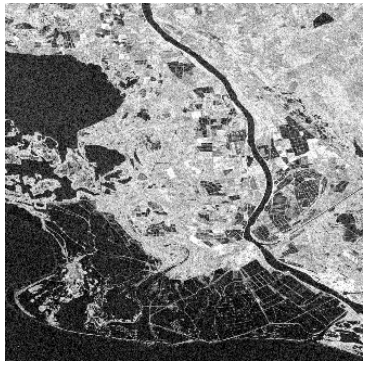

7 May 2015 (R)

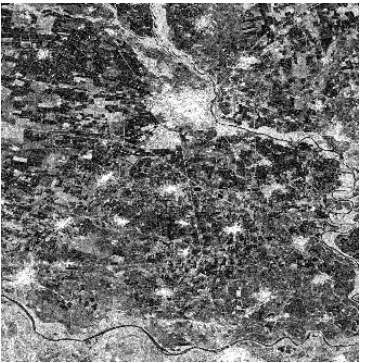

10 May 2015 (R)

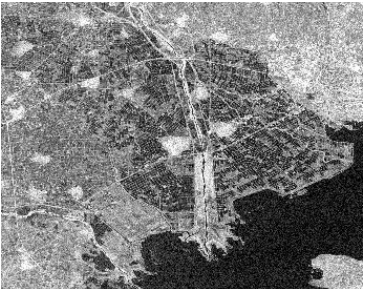

16 May 2015 (R)

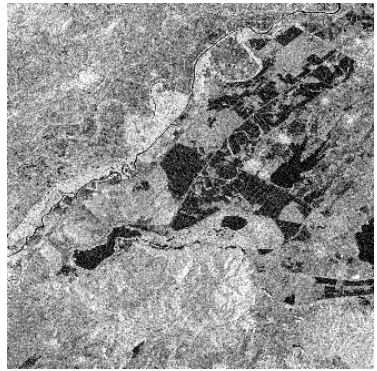

17 May 2015 (R)

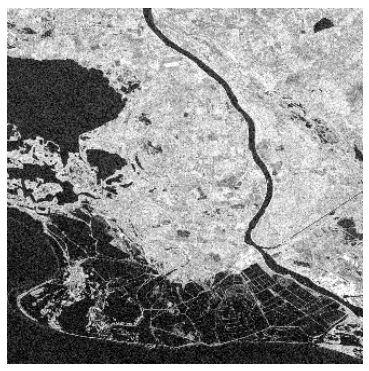

4 September 2015 (G)

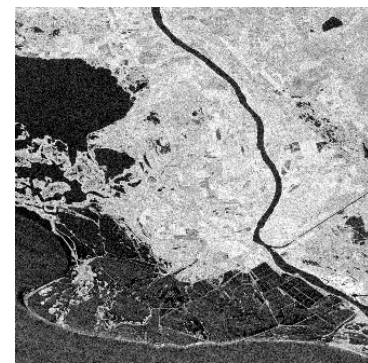

3 November 2015 (B)

Lombaria (Italy)

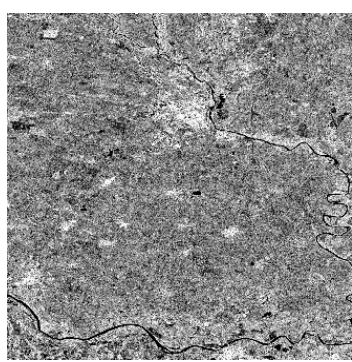

26 August 2015 (G)

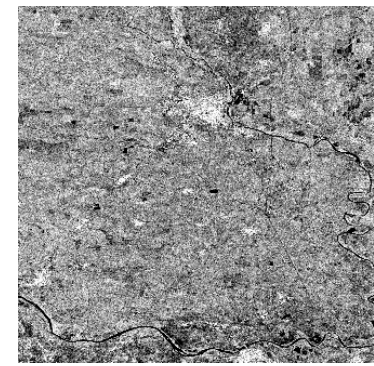

6 November 2015 (B)

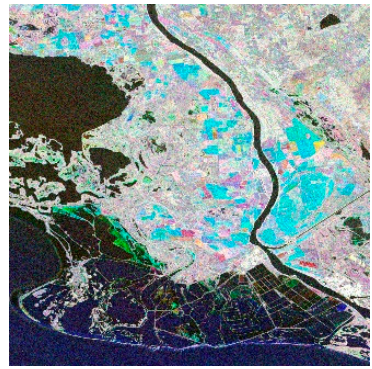

RGB

Thessaloniki (Greece)

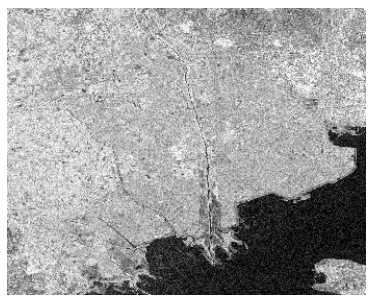

20 August 2015 (G)

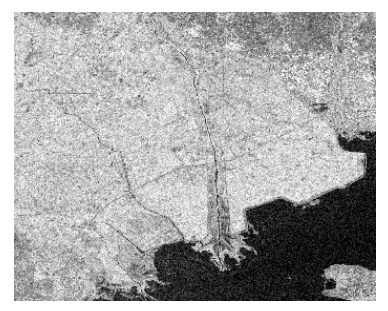

31 October 2015 (B)

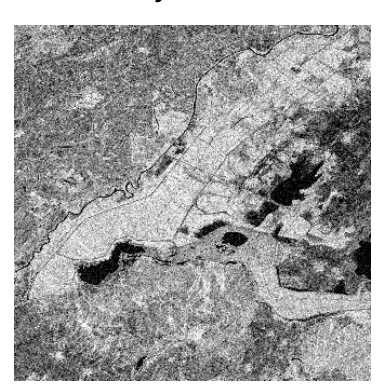

14 November 2015 (B)

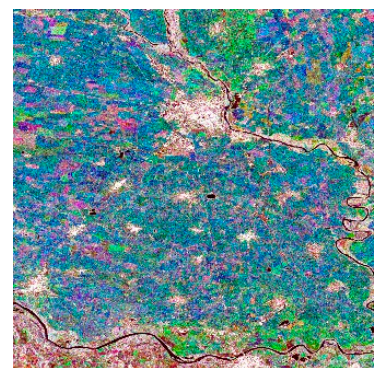

RGB

Marmma-Thrace (Turkey)

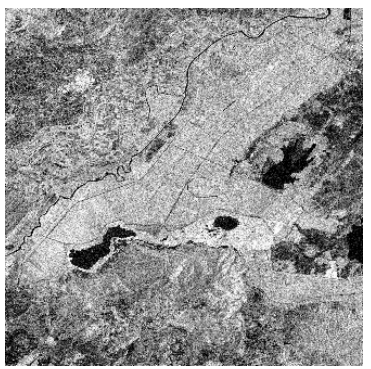

2 September 2015 (G)

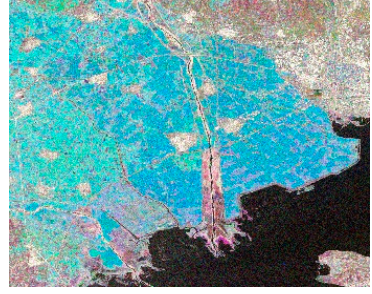

RGB

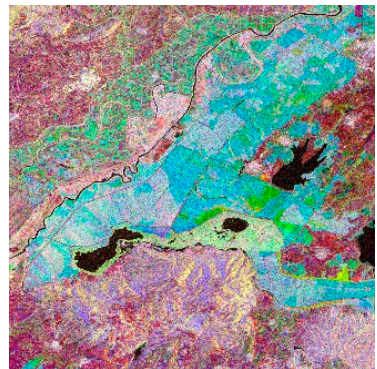

RGB

Figure 9. Columns 1-3: images of $\sigma_{V H}^{o}$ acquired at three dates (from left to right) and; Column 4: images of false color composite over the part of study sites.

After harvest, the fields can have diverse conditions, either bare and dry fields or covered with weeds in wet conditions. Fields may also be flooded due to local farming activities, e.g., in some areas fields are flooded again until January for duck hunting [46]. This event is clearly visible at the study sites in Spain (Figures $8 b-d$ and 9). However, the levels of change are quite different among the study sites due to the differences in farming activities. Meanwhile, in other regions, some small crops or 
weeds cover is possible right after the rice crop is cultivated. The radar backscatter is thus variable and in most cases can have high backscatter values. Moreover, as a result of rain which is typically high in the winter season in the Mediterranean region, the water content in bare soil increases, and this may also explain the increase of backscattering. Consequently, there is little possibility to interpret this last stage of the cultivation.

\subsection{Thresholds Selection}

Optical data sources (Spot 5, Sentinel-2, and Google Earth imagery), vector dataset and expert knowledge were used to create polygons for threshold selection. These polygons were carefully selected and digitized across eight study sites. Training areas were considered in terms of distribution and variety of rice fields (e.g., size, density, rice variety) and SAR geometry characteristic (e.g., incidence angle) to build robust training data set. These polygons used for threshold determination were then excluded from the set of polygons used for accuracy assessment. Time series analysis was carried out using all available S-1 IW Mode data between April and November 2015 (Figure 8 and Section 4.1). The overall behavior of $\sigma_{V H}^{o}$ is comparable to our previous investigations [37]. However, the dynamic range over different regions varies due to different incidence angles and farming activities. In Figure 8 , it is important to note that the response signal patterns from all sample parcels are very consistent. Therefore, we can conclude that these temporal signatures are associated with the rice crop type, and the empirical thresholds of three phenological parameters based on the $\sigma_{V H_{\text {potentia_smooth }}^{o}}$ values can be used for the identification of rice cropland. This study, we followed the approach of Nguyen et al. [15] who used phenological parameters (derived from $\sigma_{V H}^{o}$ profile) to map the rice areas of eight sites in the Mediterranean region.

For rice areas mapping, the first two key parameters, $\sigma_{D o M}^{o}$-the peak (maximum) of $\mathrm{VH}$ backscatter and $\Delta \sigma^{o}$ the amplitude backscatter (the difference between $\sigma_{D o M}^{o}$-backscatter at date of maximum backscatter and $\sigma_{D o S}^{o}$-backscatter at the begin of the growing season) are very critical. The peak and valley of $\mathrm{VH}$ backscatter (i.e., $\sigma_{D o M}^{o}, \sigma_{D o S}^{o}$ ) within the one rice-growing cycle can be identified by a local extrema algorithm. To eliminate unrealistic peaks, a threshold for VH backscatter is required. These two parameter thresholds (i.e., $\sigma_{D o M}^{o} \geq-19 \mathrm{~dB}$ and $\Delta \sigma^{o} \geq 2.5 \mathrm{~dB}$ ) were selected based on a conservative deduction from training data, limited census statistics, and expert knowledge [36]. The corresponding positions (date) and backscatter values of these two points showed in the Figure 8 where big-red dots are $\operatorname{DoS}(\mathrm{s})$ and big-blue dots are $\operatorname{DoM}(\mathrm{s})$ respectively. All areas that practice rice crops start the growing season between May-June where the lowest backscatter is observed. Rice flowering period then comes after more than one and a haft month (July-August) where S-1 respond signal in the temporal signature reaches the peak.

The third parameter, length of the season (LoS) which is defined as the temporal distance (number of days difference) between the date of beginning of season and the date when maximum backscatter value is recorded. This temporal distance has to be greater than the shortest possible rice growing cycle and smaller than the longest possible rice growing cycle. From crop calendar and our expert knowledge about rice growing season in the study areas, the threshold of temporal distance which is about 50 and 120 days, respectively. If all three conditions are met then the pixel is classified as rice, otherwise as non-rice area.

\subsection{Spatial Distribution and Comparison of S-1 Derived Rice Area with Reference Data}

The temporal backscatter signatures is shown in Figure 8 (and Figure S1 in the supplementary material) served to define specific thresholds which were applied to the S-1 time series in order to generate rice area maps for the growing season of 2015. The classification results of rice fields over eight selected sites in the Mediterranean region are shown in Figure 10. The classification accuracy has been assessed by comparing the classification results to the 2015 rice cropland vector layer for four study sites in Seville (Spain), Valencia (Spain), Lombardia (Italy), and Camargue (France); and CLC (2012) for all study sites. The confusion matrices are presented in Tables 1 and 2, respectively. 


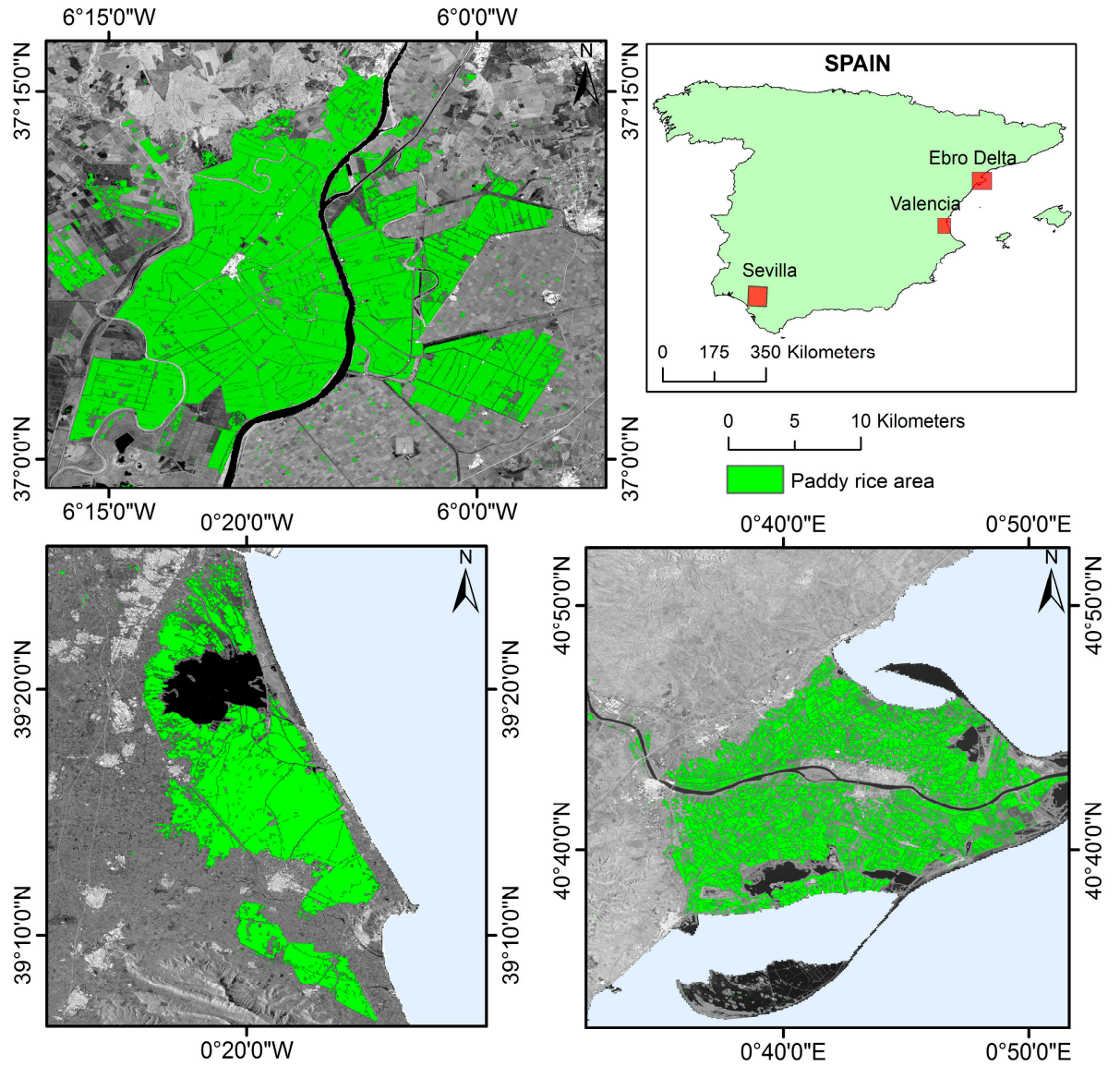

Figure 10. Rice cropland mapping in Spain.

To provide direct comparison, the classification results in all study sites: Seville and Valencia in Spain, and Thessaloniki in Greece were evaluated by using the reference vector dataset from the same year 2015; Lombardia (Italy), and Camargue (France) were evaluated by using higher spatial resolution (SPOT 5, $10 \mathrm{~m}$ ); and Earth Imagery and Sentinel-2 data were used to produce reference data to validate the classification results for the rest of study areas (Table 2). The Kappa coefficients, rice user accuracy (commission error), and rice producer accuracy (omission error) were, respectively, $0.76,70.2 \%$, and $82.7 \%$ for Mondego, Portugal; $0.87,86.8 \%$, and $89.2 \%$ for Seville, Spain; $0.85,81.7 \%$, and $93.3 \%$ for Valencia, Spain; $0.79,70.3$ and $95.3 \%$ for Ebro delta, Spain ; $0.85,80.2 \%$, and $94.0 \%$ for Camargue, France; $0.82,79.8 \%$, and $86.2 \%$ for Lombardia, Italy; $0.79,74.1 \%$, and $94.0 \%$ for Thessaloniki, Greece; and $0.76,71.1 \%$, and $84.1 \%$ for Marmara-Thrace, Turkey (Table 1). The lower accuracy level was observed in Mondego, Portugal, Ebro delta, Spain, Thessaloniki, Greece and Marmara-Thrace, Turkey, because of most rice fields in these regions associated with the small farms, and scattered throughout the mixed agricultural landscape and, thus, were easily omitted with non-rice classes. One potential source of error lies in the time difference between the reference data and the Sentinel-1 image acquisition. For example, the reference data were produced by digitizing homogenous sites of rice fields based on the image visualization and interpretation of existing high-resolution Google Earth imagery and Sentinel-2 optical data, while the classification maps were produced from 2015 S-1A data. Moreover, a number of different of farming activities during the growing season (rice varieties, water level in the fields, and density of rice plants in the fields) and SAR acquisitions period could also cause an increase in mapping errors. Although the proposed approach can properly detect most rice areas, some land cover types with high variation in backscatter values (e.g., wetland or seasonal water bodies areas) can cause commission errors. 
Table 2. Confusion matrices of the accuracy assessment.

\begin{tabular}{|c|c|c|c|c|c|}
\hline \multirow{2}{*}{ SAR Data } & \multicolumn{5}{|c|}{ Mondego, Portugal } \\
\hline & Class & Non-Rice & Rice & Total & Producer Accuracy \\
\hline & non-rice & 4251 & 71 & 4322 & $98.4 \%$ \\
\hline & rice & 35 & 167 & 202 & $82.7 \%$ \\
\hline & total & 4286 & 238 & 4524 & - \\
\hline & user accuracy & $99.2 \%$ & $70.2 \%$ & - & Kappa $=0.76$ \\
\hline & \multicolumn{5}{|c|}{ Seville, Spain } \\
\hline & Class & Non-Rice & Rice & Total & Producer Accuracy \\
\hline & non-rice & 10,057 & 140 & 10,197 & $98.6 \%$ \\
\hline & rice & 111 & 919 & 1030 & $89.2 \%$ \\
\hline & total & 10,168 & 1059 & 11,227 & - \\
\hline & user accuracy & $98.9 \%$ & $86.8 \%$ & - & Kappa $=0.87$ \\
\hline & \multicolumn{5}{|c|}{ Valencia, Spain } \\
\hline & Class & Non-Rice & Rice & Total & Producer Accuracy \\
\hline & non-rice & 6344 & 176 & 6520 & $97.3 \%$ \\
\hline & rice & 56 & 786 & 842 & $93.3 \%$ \\
\hline & total & 6400 & 962 & 7362 & - \\
\hline & user accuracy & $99.1 \%$ & $81.7 \%$ & - & Kappa $=0.85$ \\
\hline \multirow{30}{*}{ S-1 } & \multicolumn{5}{|c|}{ Ebro delta, Spain } \\
\hline & Class & Non-Rice & Rice & Total & Producer Accuracy \\
\hline & non-rice & 5637 & 256 & 5893 & $95.6 \%$ \\
\hline & rice & 30 & 606 & 636 & $95.3 \%$ \\
\hline & total & 5667 & 862 & 6529 & - \\
\hline & user accuracy & $99.5 \%$ & $70.3 \%$ & - & Kappa $=0.79$ \\
\hline & \multicolumn{5}{|c|}{ Camargue, France } \\
\hline & Class & Non-Rice & Rice & Total & Producer Accuracy \\
\hline & non-rice & 8915 & 252 & 9167 & $97.3 \%$ \\
\hline & rice & 65 & 1023 & 1088 & $94.0 \%$ \\
\hline & total & 8980 & 1275 & 10,255 & - \\
\hline & user accuracy & $99.3 \%$ & $80.2 \%$ & & Kappa $=0.85$ \\
\hline & \multicolumn{5}{|c|}{ Lombardia, Italy } \\
\hline & Class & Non-Rice & Rice & Total & Producer Accuracy \\
\hline & non-rice & 3392 & 356 & 3748 & $90.5 \%$ \\
\hline & rice & 56 & 1404 & 1460 & $86.2 \%$ \\
\hline & total & 3448 & 1760 & 5208 & - \\
\hline & user accuracy & $98.4 \%$ & $79.8 \%$ & - & Kappa $=0.82$ \\
\hline & \multicolumn{5}{|c|}{ Thessaloniki, Greece } \\
\hline & Class & Non-Rice & Rice & Total & Producer Accuracy \\
\hline & non-rice & 8915 & 357 & 9272 & $96.2 \%$ \\
\hline & rice & 65 & 1023 & 1088 & $94.0 \%$ \\
\hline & total & 8980 & 1380 & 10,360 & - \\
\hline & user accuracy & $99.3 \%$ & $74.1 \%$ & - & Карра $=0.79$ \\
\hline & \multicolumn{5}{|c|}{ Marmara-Thrace, Turkey } \\
\hline & Class & Non-Rice & Rice & Total & Producer Accuracy \\
\hline & non-rice & 22,975 & 453 & 23,428 & $98.1 \%$ \\
\hline & rice & 210 & 1112 & 1322 & $84.1 \%$ \\
\hline & total & 23,185 & 1565 & 24,750 & - \\
\hline & user accuracy & $99.1 \%$ & $71.1 \%$ & - & Kappa $=0.76$ \\
\hline
\end{tabular}

For all the study sites, CLC from 2012 were also used for comparison and checking the consistency of classification results over all study areas. Despite the limitations of the CLC data (e.g., there was a three years difference between CLC and S-1 datasets) the results suggest that the application of S-1 time series data for rice area mapping has produced consistent results for all the test sites with overall accuracies (in quotation \{\}) ranging from $77.7 \%$ to $98.9 \%$ (kappa average at 0.53 ). The average accuracies at Camargue (France), Thessaloniki (Greece) and Mondego (Portugal) are lower than that of Seville and Valencia (Spain). The results showed relatively high error rate for both commission and omission measure (see Table 3 for details). The best results were achieved over Seville and Valencia (Spain) with kappa of 0.70 (Rice omission 31.9\%) and 0.82, respectively (Rice omission 22.6\%), which is 
significantly higher than over the other regions. The worst performance (Kappa 0.37, overall accuracy: $79.9 \%$ ) was reported from Thessaloniki (Greece) with the highest commission errors (63.0\%) and omission error (nearly $30.7 \%$ ). In order to better match the spatial scale between the classification map produced and the CLC 2012 validation layer, the classification results were smoothed by gap filling using a 10 pixels $\times 10$ pixels window. The reason for this step is to compensate the smoothness level between the classified map and the CLC 2012 validation layer. The CLC 2012 product is consist of large homogeneous polygons which includes the small roads and fields boundaries, which are major source of error in the validation process. After smoothing the classified rice map a significant improvement in the overall accuracy and the kappa value is observed (Table 3). The comparison results in the Table 3 show that the poor results of accuracy comparison are not due to the errors classification output, but due to the coarser resolution of the CLC 2012 product.

Table 3. Comparisons of rice crop extraction accuracies from time series S-1 data with Corine Land cover products (CLC 2012).

\begin{tabular}{ccccc}
\hline \multirow{2}{*}{ Sites, Country } & Kappa & Overall Accuracy \% & Rice Commission \% & Rice Omission \% \\
\cline { 2 - 5 } & \multicolumn{2}{c}{ Comparison with CLC 2012 after Smoothing and with Original CLC 2012 (in \{\}) } \\
\hline Seville, Spain & $0.85\{0.70\}$ & $93.4\{88.1\}$ & $11.8\{9.3\}$ & $9.3\{31.9\}$ \\
Valencia, Spain & $0.93\{0.82\}$ & $98.9\{92.7\}$ & $3.8\{2.0\}$ & $9.5\{22.6\}$ \\
Ebro delta, Spain & $0.88\{0.52\}$ & $94.3\{77.7\}$ & $2.6\{2.8\}$ & $10.7\{49.2\}$ \\
Camargue, France & $0.46\{0.37\}$ & $87.8\{86.5\}$ & $17.7\{18.0\}$ & $62.3\{71.2\}$ \\
Lombardia, Italy & $0.60\{0.50\}$ & $83.9\{81.3\}$ & $12.6\{12.6\}$ & $37.3\{53.3\}$ \\
Thessaloniki, Greece & $0.57\{0.37\}$ & $83.5\{79.9\}$ & $29.8\{30.7\}$ & $34.1\{63.0\}$ \\
Marmara-Thrace, Turkey & $0.74\{0.52\}$ & $97.3\{94.5\}$ & $31.2\{40.7\}$ & $31.21\{60.5\}$ \\
Mondego, Portugal & $0.65\{0.43\}$ & $95.4\{98.9\}$ & $34.3\{65.7\}$ \\
\hline
\end{tabular}

\section{Conclusions}

In this paper, we investigated a phenology-based approach to map rice crop at a continental scale by using space-borne C-band SAR data. Time series of S-1A IW mode with $20 \mathrm{~m}$ spatial resolution and $\mathrm{VH}$ polarization covering eight sites in the Mediterranean region were used. The results show that the proposed approach is efficient and operationally feasible for extracting rice cropland areas with high accuracy (above 70\%) at $20 \mathrm{~m}$ spatial resolution (single-polarization) by using S-1A time series.

Our results show that dense SAR time series are critical for monitoring rice areas, which also gave an insight into the farmers' management practices within each rice cropping system.

This study emphasizes the use of annual SAR time series to generate a timely, accurate and high-resolution rice cropland spatial extent. It will be very helpful to assist decision making in the identification of rice areas for intensification, and areas for the development of irrigation as one of the necessary steps in dealing with food security related issues. Despite some current limitations of gaps in S-1A data acquisitions, this study suggests that the current and future SAR systems such as S-1B can be used complementarily to provide valuable spatial, thematic and temporal information about rice crop areas in the Mediterranean region and worldwide.

Information regarding the time of land preparation and water supply would be necessary to improve the classification in areas where the temporal signature for rice is unusual. Acquiring to such data would also help to improve the accuracy of rice cropland monitoring at the continental scale using S-1 time series.

Supplementary Materials: The following are available online at www.mdpi.com/2073-4441/9/6/392/s1. Figure S1 Rice cropland map of 8 study sites in the Mediterranean region.

Acknowledgments: The authors would like to thank VIED (Vietnam International Education Development) and OeAD (Österreichischer Austauschdienst) for their support during the studying period. We also thank Ali Iftikhar for the valuable comments on the paper in its early version. 
Author Contributions: Duy Ba Nguyen and Wolfgang Wagner conceived and designed the study. The algorithm was developed by Duy Ba Nguyen and the experiments were implemented by Duy Ba Nguyen with guiding comments by Wolfgang Wagner. SAR data pre-processing and geophysical parameters retrieval were performed by Duy Ba Nguyen. Duy Ba Nguyen wrote a first draft version of the manuscript and produced all graphics. Wolfgang Wagner suggested detailed improvements. All authors provided assistance in editing and organizing the manuscript.

Conflicts of Interest: The authors declare no conflict of interest.

\section{References}

1. Food and Agriculture Organization of the United Nations (FAO). The State of Food and Agriculture; FAO: Rome, Italy, 2015.

2. Van der Sande, C.J.; De Jong, S.M.; De Roo, A.P.J. A segmentation and classification approach of IKONOS-2 imagery for land cover mapping to assist flood risk and flood damage assessment. Int. J. Appl. Earth Obs. Geoinform. 2003, 4, 217-229. [CrossRef]

3. Koellner, T.; Scholz, R.W. Assessment of land use impacts on the natural environment. Int. J. Life Cycle Assess. 2006, 13, 32-48.

4. Koellner, T.; Baan, L.; Beck, T.; Brandão, M.; Civit, B.; Goedkoop, M.; Margni, M.; Canals, L.M.; Müller-Wenk, R.; Weidema, B.; et al. Principles for life cycle inventories of land use on a global scale. Int. J. Life Cycle Assess. 2012, 18, 1203-1215. [CrossRef]

5. Roy, P.; Ijiri, T.; Nei, D.; Orikasa, T.; Okadome, H.; Nakamura, N.; Shiina, T. Life cycle inventory (LCI) of different forms of rice consumed in households in Japan. J. Food Eng. 2009, 91, 49-55. [CrossRef]

6. Blengini, G.A.; Busto, M. The life cycle of rice: LCA of alternative agri-food chain management systems in Vercelli (Italy). J. Environ. Manag. 2009, 90, 1512-1522. [CrossRef] [PubMed]

7. Roy, P.; Nei, D.; Orikasa, T.; Xu, Q.; Okadome, H.; Nakamura, N.; Shiina, T. A review of life cycle assessment (LCA) on some food products. J. Food Eng. 2009, 90, 1-10. [CrossRef]

8. Weng, X.-Y.; Zheng, C.-J.; Xu, H.-X.; Sun, J.-Y. Characteristics of photosynthesis and functions of the water-water cycle in rice (Oryza sativa) leaves in response to potassium deficiency. Physiol. Plant. 2007, 131, 614-621. [CrossRef] [PubMed]

9. Genovese, G.; Vignolles, C.; Negre, T.; Passera, G. A methodology for a combined use of normalised difference vegetation index and CORINE land cover data for crop yield monitoring and forecasting. A case study on Spain. Agronomie 2001, 21,91-111. [CrossRef]

10. Agency, E.E. Clc2006 Technical Guidelines; European Environment Agency: Copenhagen, Denmark, 2007.

11. Agency, E.E. Clc2012: Addendum to clc2006 Technical Guidelines; European Environment Agency: Copenhagen, Denmark, 2012.

12. Kurosu, T.; Fujita, M.; Chiba, K. Monitoring of rice crop growth from space using the ERS-1 C-band SAR. IEEE Trans. Geosci. Remote Sens. 1995, 33, 1092-1096. [CrossRef]

13. Toan, T.L.; Ribbes, F.; Wang, L.F.; Floury, N.; Ding, K.H.; Kong, J.A.; Fujita, M.; Kurosu, T. Rice crop mapping and monitoring using ERS-1 data based on experiment and modeling results. IEEE Trans. Geosci. Remote Sens. 1997, 35, 41-56. [CrossRef]

14. Bouvet, A.; Le Toan, T.; Lam-Dao, N. Monitoring of the rice cropping system in the Mekong Delta using ENVISAT/ASAR dual polarization data. IEEE Trans. Geosci. Remote Sens. 2009, 47, 517-526. [CrossRef]

15. Bouvet, A.; Le Toan, T. Use of ENVISAT/ASAR wide-swath data for timely rice fields mapping in the Mekong River Delta. Remote Sens. Environ. 2011, 115, 1090-1101. [CrossRef]

16. Nguyen, D.; Clauss, K.; Cao, S.; Naeimi, V.; Kuenzer, C.; Wagner, W. Mapping rice seasonality in the Mekong Delta with multi-year Envisat Asar Wsm data. Remote Sens. 2015, 7, 15868-15893. [CrossRef]

17. Choudhury, I.; Chakraborty, M. SAR signature investigation of rice crop using RADARSAT data. Int. J. Remote Sens. 2006, 27, 519-534. [CrossRef]

18. Panigrahy, S.; Manjunath, K.R.; Chakraborty, M.; Kundu, N.; Parihar, J.S. Evaluation of RADARSAT standard beam data for identification of potato and rice crops in india. ISPRS J. Photogramm. Remote Sens. 1999, 54, 254-262. [CrossRef]

19. Panigrahy, S.; Jain, V.; Patnaik, C.; Parihar, J.S. Identification of Aman Rice Crop in Bangladesh using temporal C-band SAR-A feasibility study. J. Indian Soc. Remote Sens. 2012, 40, 599-606. [CrossRef] 
20. Kaojarern, S.-A.; Delsol, J.P.; Toan, T.L.; Kam, S.P. Assessment of multi-temporal radar imagery in mapping land system for rainfed lowland rice in Northeast Thailand. In Proceedings of the Map Asia 2002, Bangkok, Thailand, 7-9 September 2002.

21. Li, Z.; Sun, G.; Wooding, M.; Pang, Y.; Dong, Y.; Chen, E.; Tan, B. Rice monitoring using envisat Asar data in China. In Proceedings of the 2004 Envisat \& ERS Symposium, Salzburg, Austria, 6-10 September 2004.

22. Chen, J.; Lin, H.; Pei, Z. Application of ENVISAT ASAR data in mapping rice crop growth in Southern China. IEEE Geosci. Remote Sens. Lett. 2007, 4, 431-435. [CrossRef]

23. Yu, G.; Yang, S.; Zhao, X.; Shen, S. Application of ENVISAT ASAR data to rice monitoring in Jiangsu Province, China. In Proceedings of the 2010 International Conference on Multimedia Technology, Ningbo, China, 29-31 October 2010.

24. Liew, S.C.; Kam, S.-P.; Tuong, T.-P. Application of multitemporal ERS-2 synthetic aperture radar in delineating rice cropping systems in the Mekong River Delta, Vietnam. IEEE Trans. Geosci. Remote Sens. 1998, 36, 1412-1420. [CrossRef]

25. Lopez-Sanchez, J.M.; Ballester-Berman, J.D.; Hajnsek, I. First results of rice monitoring practices in Spain by means of time series of TerraSAR-X dual-pol images. IEEE J. Sel. Topics Appl. Earth Obs. Remote Sens. 2011, 4, 412-422. [CrossRef]

26. Özküralpli, İ; Sunar, F. Monitoring crop growth in rice padies in the thrace-meriç basin with multitemporal RADARSAT-1 satellite images. In Proceedings of the ISPRS Commission VII-Conference on Information Extraction From SAR and Optical Data, with Emphasis on Developing Countries, Istanbul, Turkey, 15-17 May 2007.

27. Rosenqvist, A. Temporal and spatial characteristics of irrigated rice in JERS-1 L-band SAR data. Int. J. Remote Sens. 1999, 20, 1567-1587. [CrossRef]

28. Chakraborty, M.; Panigrahy, S. A processing and software system for rice crop inventory using multi-date RADARSAT ScanSAR data. ISPRS J. Photogramm. Remote Sens. 2000, 55, 119-128. [CrossRef]

29. Tan, Q.; Hu, J.; Bi, S.; Liu, Z. A study on rice field edge extraction in RADARSAT SAR images. In Proceedings of the 2004 IEEE Interbational Geoscience and Remote Sensing Symposium, Anchorage, AK, USA, 20-24 September 2004.

30. Zhang, Y.; Wang, C.; Wu, J.; Qi, J.; Salas, W.A. Mapping paddy rice with multitemporal ALOS/PALSAR imagery in Southeast China. Int. J. Remote Sens. 2009, 30, 6301-6315. [CrossRef]

31. Dao, N.L. Rice Crop Monitoring Using New Generation Synthetic Aperture Radar (SAR) Imagery. Ph.D. Thesis, University of Southern Queensland, Darling Heights, QLD, Australia, 2009.

32. Lam-Dao, N.; Apan, A.; Le-Toan, T.; Young, F.; Le-Van, T.; Bouvet, A. Towards an operational system for rice crop inventory in the Mekong River Delta, Vietnam using ENVISAT-ASAR data. In Proceedings of the 7th FIG Regional Conference, Spatial Data Serving People: Land Governance and the Environment—Building the Capacity, Hanoi, Vietnam, 19-22 October 2009.

33. Fan, W.; Chao, W.; Hong, Z.; Bo, Z.; Yixian, T. Rice crop monitoring in South China with RADARSAT-2 quad-polarization SAR data. IEEE Geosci. Remote Sens. Lett. 2011, 8, 196-200.

34. Schmitt, A.; Brisco, B. Wetland monitoring using the curvelet-based change detection method on polarimetric SAR imagery. Water 2013, 5, 1036-1051. [CrossRef]

35. Yang, S.B.; Shen, S.H.; Zhao, X.Y.; Gao, W.; Jackson, T.J.; Wang, J.; Chang, N.B. Assessment of RADARSAT-2 quad-polarization SAR data in rice crop mapping and yield estimation. Remote Sens. Model. Ecosyst. Sustain. IX 2012. [CrossRef]

36. Nguyen, D.B.; Gruber, A.; Wagner, W. Mapping rice extent and cropping scheme in the Mekong Delta using Sentinel-1A data. Remote Sens. Lett. 2016, 7, 1209-1218. [CrossRef]

37. European Commission; DG AGRI. EU Rice Economic Fact Sheet. Available online: http://ec.europa.eu/ agriculture/cereals/trade/rice/economic-fact-sheet_en.pdf (accessed on 31 May 2017).

38. Ferrero, A.; Tinarelli, A. Rice cultivation in the EU ecological conditions and agronomical practices. In Pesticide Risk Assessment in Rice Paddies: Theory and Pratice; Ettore, C., Dimitrios, K., Eds.; Elsevier: Amsterdam, The Netherlands, 2007; pp. 1-24.

39. Calha, I.M.; Machado, C.; Rocha, F. Resistance of alisma plantago aquatica to sulfonylurea herbicides in portuguese rice fields. In Biology, Ecology and Management of Aquatic Plants: Proceedings of the 10th International Symposium on Aquatic Weeds, European Weed Research Society; Caffrey, J., Barrett, P.R.F., Ferreira, M.T., Moreira, I.S., Murphy, K.J., Wade, P.M., Eds.; Springer: Dordrecht, The Netherlands, 1999; pp. 289-293. 
40. Silva, E.; Batista, S.; Viana, P.; Antunes, P.; Serôdio, L.; Cardoso, A.T.; Cerejeira, M.J. Pesticides and nitrates in groundwater from oriziculture areas of the 'Baixo Sado' region (Portugal). Int. J. Environ. Anal. Chem. 2006, 86, 955-972. [CrossRef]

41. Spot Take5. Available online: https://spot-take5.org/client/\#/products/ (accessed on 31 May 2017).

42. The Institute of Statistics and Cartography of Andalusia. Available online: http://www.juntadeandalucia. es /institutodeestadisticaycartografia/sima/ficha.htm?mun=41902 (accessed on 31 May 2017).

43. The ERMES (An Earth Observation Model Based Rice Information Service). Available online: http://ermes. dlsi.uji.es/prototype/ (accessed on 31 May 2017).

44. The EOX: Maps. Available online: https://s2maps.eu/ (accessed on 31 May 2017).

45. Brisco, B.; Brown, R.J.; Snider, B.; Sofko, G.J.; Koehler, J.A.; Wacker, A.G. Tillage effects on the radar backscattering coefficient of grain stubble fields. Int. J. Remote Sens. 1991, 12, 2283-2298. [CrossRef]

46. Rodríguez Díaz, J.A.; Weatherhead, E.K.; Knox, J.W.; Camacho, E. Climate change impacts on irrigation water requirements in the guadalquivir river basin in Spain. Reg. Environ. Chang. 2007, 7, 149-159. [CrossRef]

47. Sharma, S.D. Rice Origin Antiquity and History; Taykor \& Francis: New York, NY, USA, 2010; ISBN 978-1-4398-4056-6.

(C) 2017 by the authors. Licensee MDPI, Basel, Switzerland. This article is an open access article distributed under the terms and conditions of the Creative Commons Attribution (CC BY) license (http:/ / creativecommons.org/licenses/by/4.0/). 